\title{
Data Integration, Reservoir Response, and Application
}

\author{
Robert Will ${ }^{\text {a† }}$, Valerie Smith ${ }^{\mathrm{b}}$, Don Lee ${ }^{\mathrm{c}}$, Ozgur Senel ${ }^{\mathrm{d}}$
}

\begin{abstract}
The microseismic activity observed in and around a geologic formation undergoing carbon dioxide $\left(\mathrm{CO}_{2}\right)$ injection is a combination of natural, or "background", microseismicity plus that activity which is induced by injection operations. Since injection pressure within storage target formations are maintained safely below fracture pressure this induced activity typically originates at natural pre-existing zones of mechanical weakness presented by structural or stratigraphic features. The combination of mechanical properties and in-situ stresses dictate the focal mechanism for microseismic emissions, an understanding of which facilitates the use of observed microseismicity for regulatory compliance and project management.
\end{abstract}

Under favorable conditions microseismic activity may be unambiguously correlated with structural and/or stratigraphic features directly observed in seismic data, thus providing strong constraints to interpretation of observed microseismicity for focal mechanisms. However, in many cases, such as at the Illinois Basin - Decatur Project (IBDP), this direct correlation is elusive and other indirect support is required. Analysis of microseismicity at IBDP has been performed within the context of the integrated reservoir and mechanical earth models developed as part of the site characterization and monitoring program. The IBDP integrated modeling workflow involved continuous and geotechnically consistent data integration for geologic modeling, calibrated flow simulation, three-dimensional (3D) Mechanical Earth Model, and coupled hydromechanical simulation. Using the coupled model, scenario-based forward modeling of microseismicity was performed for hypothetical focal mechanisms inferred from observed data.

The experience gained at IBDP illustrates the importance of integrated modeling in the interpretation of microseismic activity for focal mechanisms and provides valuable insights into critical data gaps which could be the target of future basic research efforts.

\section{Keywords}

Microseismic, Integration, Modeling, Prediction, Simulation, Geomechanics

\section{Introduction}

Seismic data acquisition, processing, and analysis have provided a deeper insight into the microseismicity at the Illinois Basin - Decatur Project (IBDP) site in Illinois, USA. The acquisition, processing and data analysis began in late 2009 and has continued past the one million tonne (and injection shut-in) milestone reached in November 2014 and into 
the post-injection site closure period. In this paper it will be shown how these data have been integrated with other geoscience and engineering data to form a multi-disciplinary and geotechnically consistent conceptual model of the microseismic source mechanism.

The importance of geological context as part of the IBDP microseismic monitoring and the process by which this has been developed is discussed. This is followed by a brief discussion of the hydro-mechanical "reservoir response" to carbon dioxide $\left(\mathrm{CO}_{2}\right)$ injection and the model-based workflow used to develop an initial working model for the microseismic source mechanism at IBDP. Finally, ways in which the resulting model is being used to support operational activities for a second project in Illinois are presented.

While having many intermediate milestones, one of the overarching objectives of the IBDP microseismic monitoring effort was to develop and demonstrate methods for technically rigorous and economically viable monitoring of microseismicity for $\mathrm{CO}_{2}$ sequestration projects.

\section{Geologic Context}

\subsection{The Role of the Geologic Model}

The geologic context in the interpretation and understanding of the microseismic data at the IBDP is imperative and foundational. The static model provides the framework for subsequent numerical computations of transient hydrodynamic and geomechanical processes. The microseismicity observed at the IBDP site is initiated at distance from the injection well where reservoir properties, hydraulic pressure, and stress-strain state are not directly measured. As a result, reservoir characteristics and hydromechanical conditions in the vicinity of the microseismic source may only be estimated by extrapolation within an accurate model.

While certain microseismic source mechanism characteristics may be inverted directly from microseismic observations alone through processes such as fault plane solution (FPS) analysis and moment tensor inversion ${ }^{1}$, the results of such analyses lack sufficient uniqueness or completeness to solely form the basis of a geologically consistent interpretation of the source mechanism. This is particularly true when the features responsible for microseismic activity are not evident at the resolution of surface seismic data during site characterization. In such cases, the results of microseismic data inversions must be interpreted within as accurate a geological context as possible to help compensate for this lack of surface seismic resolution. Prior to the IBDP data acquisition campaign there existed little subsurface information in the area to support the development of such a model. Will et al. (2014) provide a historical review of the work done to integrate microseismic observations, indirect geologic and geophysical indicators, and forward modeling for development of a working conceptual model of the microseismic source mechanisms at the IBDP site. 


\subsection{Key Elements of the Static Model}

The modeling workflow utilized for microseismic analysis at the IBDP involved parallel development of static geologic and geomechanical models followed by coupled flow and geomechanical modeling. In this workflow it is important that the flow simulation and geomechanical modeling paths share the same static geologic framework. In addition the static models, geological and geomechanical, must each incorporate key properties and features controlling these processes. These are:

- Primary structural and stratigraphic framework for the reservoir and overlying formations;

- Other discrete components that may be hydrodynamically or mechanically important such as faults or fractures;

- Formation properties.

Each of the abovementioned model elements may be constrained by one or more direct (well log/core/test) or indirect (seismic or gravity/magnetics) measurements. The data used for the IBDP modeling are summarized in Table 1.

Multi-domain measurements are combined using geostatistical integration methods, which optimize the relative contributions of sparsely distributed hard data points (well logs) and three-dimensional (3D) soft estimates (seismic inversion products), to constrain

the inter-well space. While such geostatistical methods are commonly used for population of reservoir models with hydrodynamic properties (porosity and permeability), these same methods are used to combine well data based geomechanical property estimates with seismic inversion products in the static 3D mechanical earth modeling (MEM) workflow.

The static geological and geomechanical models should be considered best estimates which may be systematically modified during the dynamic model calibration process. Such modifications are required as the result of features which are not directly observed or may not be directly resolved with the static site characterization dataset. Two specific examples which are operative for the IBDP are:

- Low permeability silt- or clay-rich layers which may not be interpreted from seismic data or correlated from well logs but the impact of which are observed in long term pressure monitoring data (Section 3, Figure 11);

- Sub-seismic resolution mechanical features which are not observed in seismic data but may be inferred from microseismic observations.

The treatments of these considerations for the IBDP are discussed following. 
Table 1 - Model components and data sources.

\begin{tabular}{|c|c|c|c|}
\hline & Structure/Stratigraphy & Discrete Components & Properties \\
\hline Well logs & $\begin{array}{l}\text { - Geologic tops } \\
\text { - Image log dip } \\
\text { estimates }\end{array}$ & $\begin{array}{l}\text { - Image log fracture } \\
\text { interpretation }\end{array}$ & $\begin{array}{l}\text { Hydrodynamic } \\
\text { properties } \\
\text { - Mechanical } \\
\text { properties }\end{array}$ \\
\hline Core & $\begin{array}{l}\text { - Formation breaks } \\
\text { - Bedding planes }\end{array}$ & $\begin{array}{l}\text { - Fault and fracture } \\
\text { interpretation }\end{array}$ & $\begin{array}{l}\text { - Hydrodynamic } \\
\text { properties } \\
\text { - Mechanical } \\
\text { properties } \\
\end{array}$ \\
\hline Well Test & $\begin{array}{l}\text { - Reservoir thickness } \\
(\mathrm{k}-\mathrm{H})\end{array}$ & $\begin{array}{l}\text { - Sealing faults } \\
\text { - Fracture flow }\end{array}$ & $\begin{array}{l}\text { - Permeability (k-H) } \\
\text { - Total compressibility }\end{array}$ \\
\hline Seismic & - Horizon interpretation & $\begin{array}{l}\text { - Fault interpretation } \\
\text { - Inferred fracture } \\
\text { sets (seismic } \\
\text { anisotropy) } \\
\end{array}$ & $\begin{array}{l}\text { - Porosity (inversion) } \\
\text { - Elastic properties } \\
\text { (inversion) }\end{array}$ \\
\hline
\end{tabular}

Evolution of the IBDP Static Geological and Mechanical Earth Models

The static model has evolved through an ongoing process of data collection and model updates beginning with the initial site characterization conducted in 2007 to 2008 and continuing to current time (as of the first quarter of 2015) with wireline data and core being collected from an injection well (CCS2) under construction for a second project called the Illinois Industrial Carbon Capture and Storage (ICCS) Project located near the IBDP site in Decatur, IL. The IBDP geoscience data acquisition campaign is described in Site Characterization, Modeling, and Monitoring Plans, Topical Report 3, An Assessment of Geological Carbon Sequestration Options in the Illinois Basin: Phase III. Important model development milestones are summarized in Table 2.

Key features of the process are:

- Geophysical logging, including advanced measurements such as Nuclear Magnetic Resonance and Sonic Scanner* acoustic scanning platform, followed by refined petrophysical and geomechanical log analysis, which provides accurate estimates of formation lithology and hydrodynamic properties.

- FMI* fullbore formation microimager images that give direct understanding of the sedimentary depositional features.

- Whole and sidewall core acquisition, followed by petrophysical and mechanical testing to calibrate and/or verify well log estimates of formation mechanical properties. 
- Surface seismic data acquisition and processing allowing detailed stratigraphic interpretation.

- 3D pre-stack (elastic) seismic inversion providing 3D volumes of porosity and elastic properties for conditioning the 3D interpolation of hydrodynamic and geomechanical properties.

- Calibration of reservoir simulation and geomechanical models and feedback of calibration modifications to static modelers.

Figure 1 shows the petrophysical data and Elemental Analysis (ELAN) of the IBDP Verification Well (VW1) data used in development of the geologic and reservoir models. Geophysical log data quality was very good and showed a high degree of consistency between multiple wells. The Mt. Simon Formation is sub-divided into 6 units labeled from bottom to top as units A through E. The Mt. Simon A is further subdivided into lower and upper portions by a hydraulic boundary discussed in Freiburg et al.. Figure 2 shows the mechanical data from the one-dimensional (1D) MEM of VW1. These data, along with similar analyses in two other wells are used to guide interpolation of mechanical properties and initial stress conditions in the 3D MEM. Figure 3 shows the key input data sources and static geologic model components. 3D seismic interpretations, 3D seismic inversion products, and geophysical logs have been combined through geostatistical methods to create the 3D structure and geocellular property models. The 3D pososity distribution was created through co-located co-simulation of 3D seismic Acoustic Impedance inversion against geophysical well logs. Permeability was computed through co-located co-simulation of permeability logs (ELAN) against porosity using an appropriate transform. Mechanical 3D property distributions (Figure 4) were computed by simulation of log derived moduli and density using seismic Elastic Inversion products (elastic moduli and density) as a trend, followed by computation of 3D mechanical properties (Young's Modulus, Poisson Ratio, and UCI) using analytical and empirical relations derived from 1D MEM's. Although the petrophysical and mechanical property distributions shown in Figures 3 and 4 are generated through Gaussian Simulation and represent only a single potential solution, conditioning of 3D property interpolation with 3D seismic data reduces solution uncertainty. Later calibration of the reservoir model to injector and monitor well pressures suggests that the major source of hydraulic uncertainty lies in features which are not fully constrained by either log or seismic data.

Optimal integration and utilization of these data has depended on tight integration between static modelers and end users (reservoir and geomechanical engineers). Routine inter-disciplinary communications across geology, reservoir engineering, geomechanics, and seismology facilitated clear definition of static model requirements as well as feedback of static model updates which are driven by reservoir and geomechanical model calibration. 
Table 2 - Static Model Development Milestones

\begin{tabular}{|c|c|c|c|c|}
\hline & $\begin{array}{c}\text { Structure/Stratigraphy/Discrete } \\
\text { Features }\end{array}$ & Hydrodynamic Properties & Mechanical Properties & Utility \\
\hline 2008 Preliminary & $\begin{array}{l}\text { - Layer cake stratigraphy defined by well } \\
\text { tops from analog well } 60 \text { miles away from } \\
\text { proposed drilling location. } \\
\text { - No discrete features }\end{array}$ & $\begin{array}{l}\text { - Uniform zonal porosity and } \\
\text { permeability } \\
\text { - Assigned using logs from } \\
\text { analog well } 60 \text { miles away } \\
\text { from proposed drilling } \\
\text { location. }\end{array}$ & - No MEM & $\begin{array}{l}\text { - Site characterization. } \\
\text { - Basis for initial reservoir } \\
\text { simulation model. }\end{array}$ \\
\hline 2010 Update & $\begin{array}{l}\text { - Layer cake stratigraphy: well tops from } \\
\text { CCS1. } \\
\text { - No discrete features }\end{array}$ & $\begin{array}{l}\text { - Stochastic zonal porosity and } \\
\text { permeability } \\
\text { - Conditioned to CCS1 well } \\
\text { logs }\end{array}$ & - 1D MEM for CCS1 & $\begin{array}{l}\text { - Updated site characterization } \\
\text { - Basis for initial reservoir } \\
\text { simulation plume predictions. }\end{array}$ \\
\hline 2011 Update & $\begin{array}{l}\text { - Stratigraphy: } 2010 \text { 3D seismic survey and } \\
\text { well top control from wells CCS1 and } \\
\text { VW1. } \\
\text { - No discrete features }\end{array}$ & $\begin{array}{l}\text { - Stochastic zonal porosity and } \\
\text { permeability } \\
\text { - Conditioned to CCS1 and } \\
\text { VW1 well logs and } 2010 \\
\text { seismic inversion products. }\end{array}$ & $\begin{array}{l}\text { - } 1 \mathrm{D} \text { MEM for well VW1 } \\
\text { 3D stochastic zonal } \\
\text { mechanical properties } \\
\text { conditioned to well CCS1 1D } \\
\text { MEM }\end{array}$ & $\begin{array}{l}\text { - Update site characterization } \\
\text { - Basis for final Class VI permit } \\
\text { reservoir simulation area of } \\
\text { review (nb1) calculations } \\
\text { - Basis for preliminary Finite } \\
\text { Element Model (FEM) (nb2) } \\
\text { modeling. }\end{array}$ \\
\hline 2013 Update & $\begin{array}{l}\text { - Stratigraphy: } 2011 \text { extended 3D seismic } \\
\text { survey and well top control from wells } \\
\text { CCS1, VW1, and VW2. } \\
\text { - Provisional fault interpretation } \\
\text { - Mechanical features inferred from } \\
\text { microseismic data. }\end{array}$ & $\begin{array}{l}\text { - Stochastic zonal porosity and } \\
\text { permeability } \\
\text { - Conditioned to CCS1, VW1, } \\
\text { and VW2 well logs and } 2011 \\
\text { seismic inversion products. }\end{array}$ & $\begin{array}{l}\text { - } 1 \text { D MEM well VW2 } \\
\text { - Updated 3D stochastic zonal } \\
\text { mechanical properties } \\
\text { conditioned to well CCS1, } \\
\text { VW1, and VW2 1D MEMs. } \\
\text { - Included mechanical features } \\
\text { inferred from microseismic } \\
\text { data }\end{array}$ & $\begin{array}{l}\text { - Update site characterization } \\
\text { - Basis for updated FEM and } \\
\text { preliminary microseismic } \\
\text { prediction research. }\end{array}$ \\
\hline
\end{tabular}




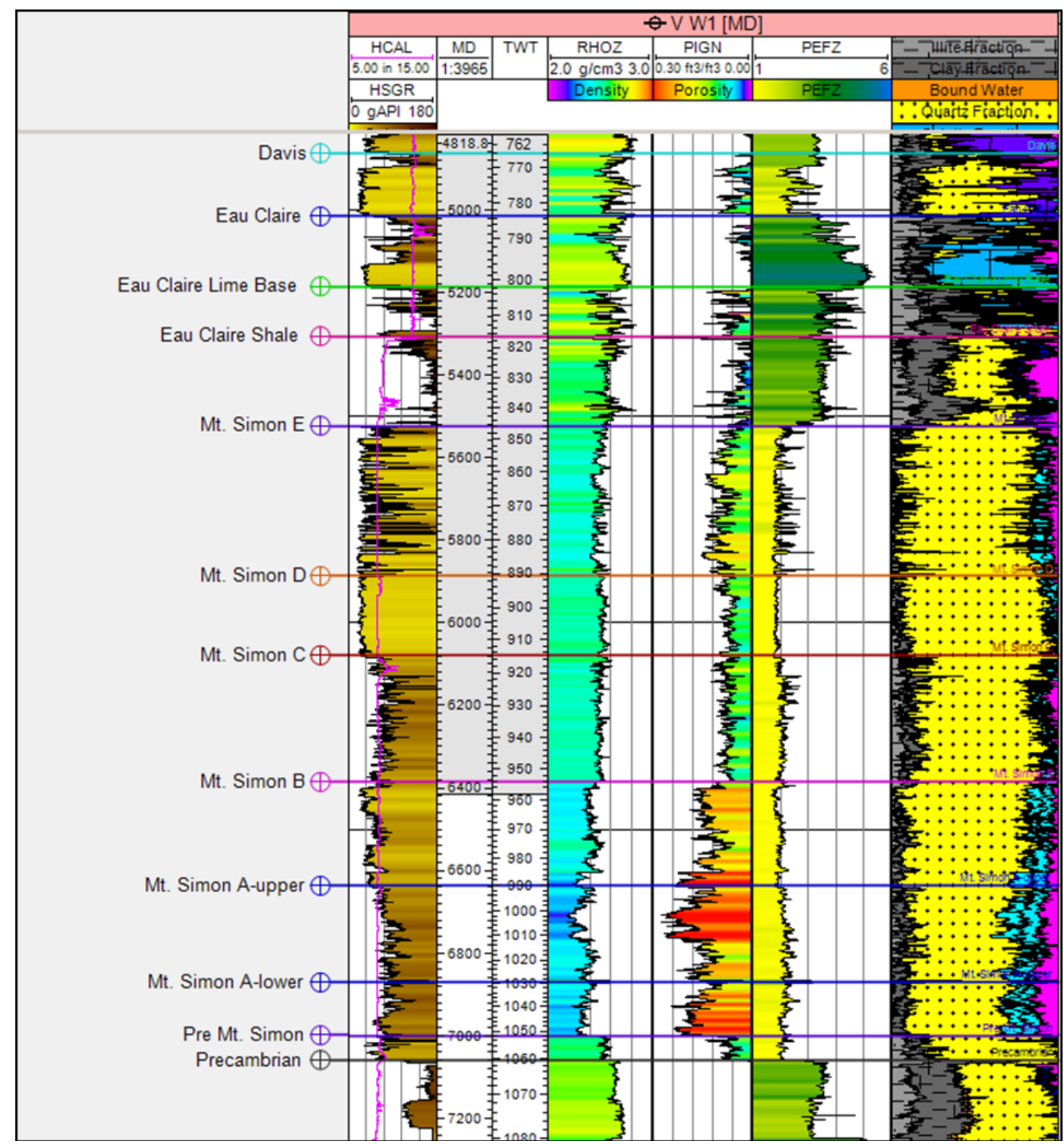

Figure 1 - Well VW1 petrophysical data. From left to right: Caliper and gamma ray, density, porosity, photoelectric effect, mineralogy and fluid saturation fractional components from ELAN analysis. 

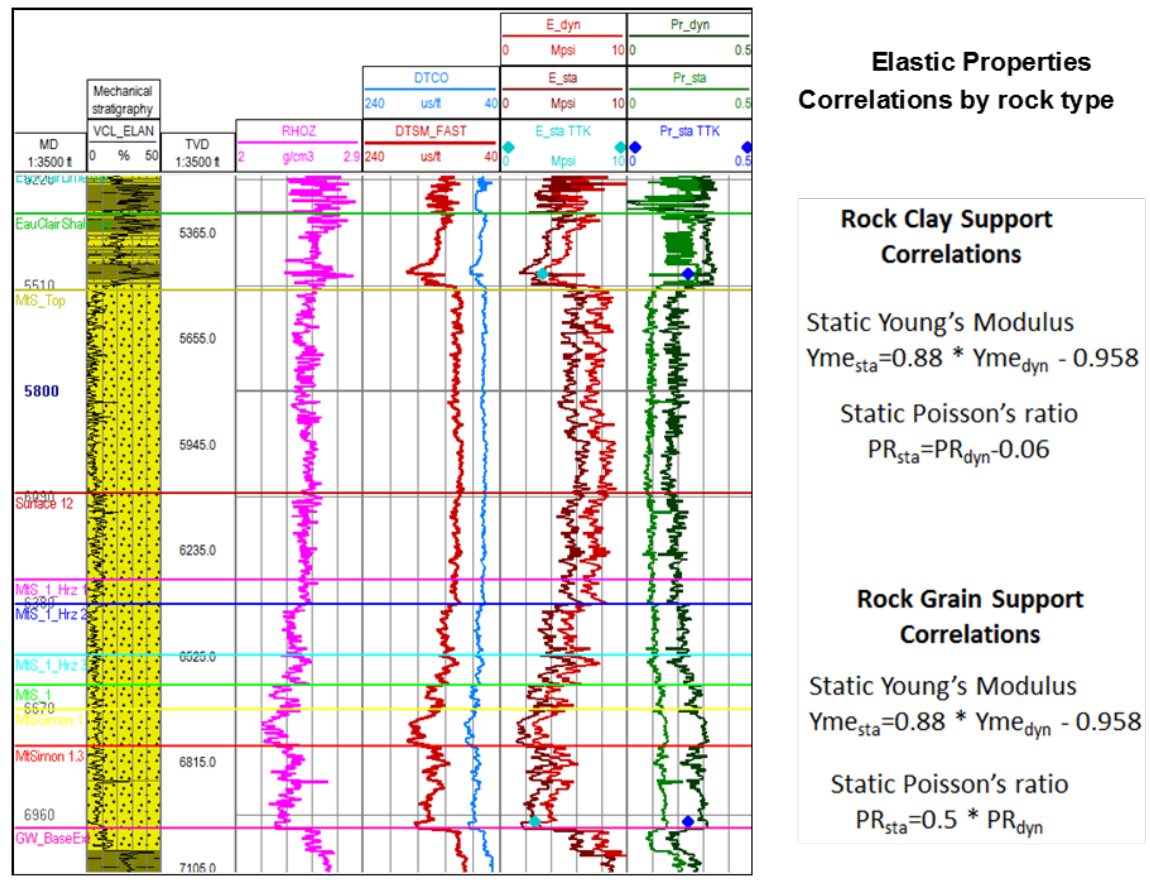

Figure 2: VW1 Elastic Properties. From left to right: Measured Depth (in feet), Mechanical Stratigraphy and Clay Content (black), True Vertical Depth (in feet), Density (pink), Shear (burgundy) and Compressional (blue) Sonic, Static (brown) and Dynamic (burgundy) Young Modulus, Static (green) and Dynamic (dark green).

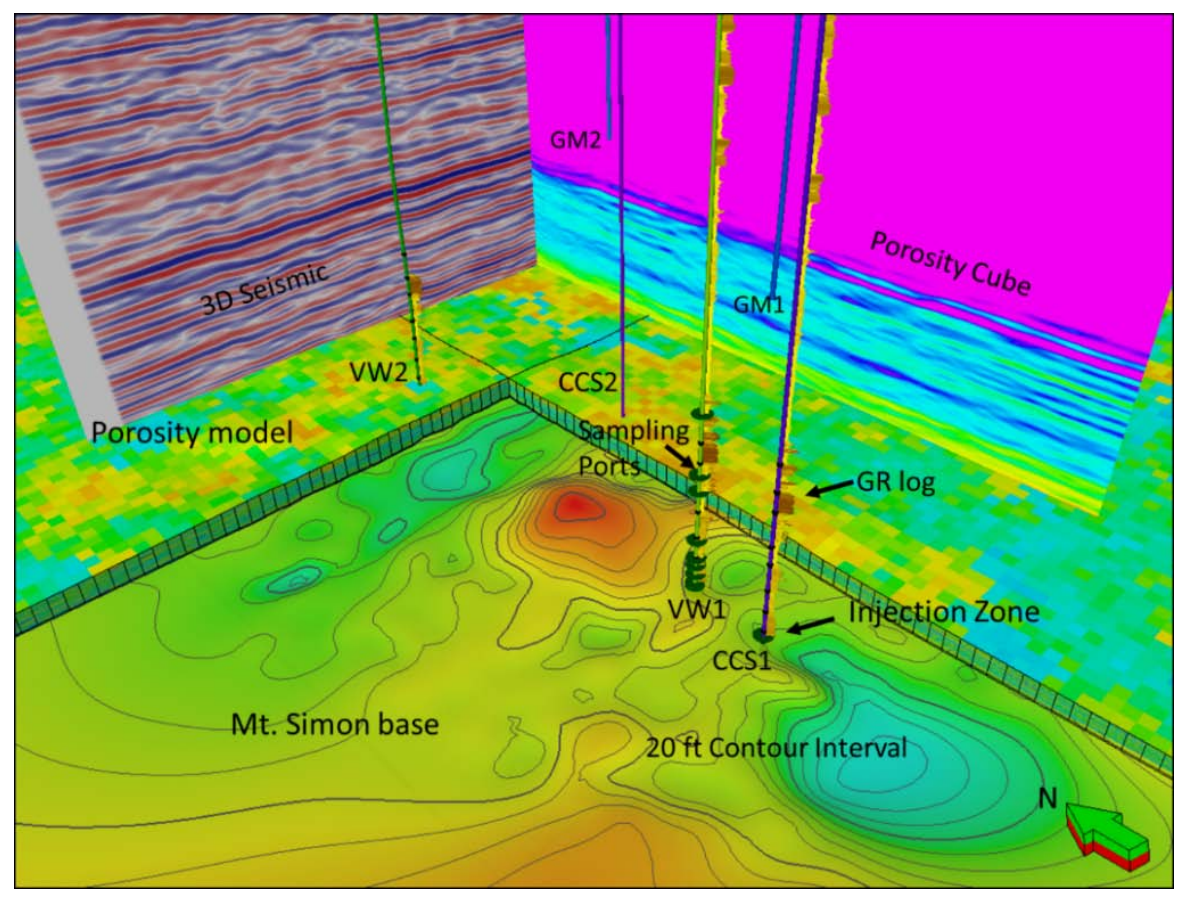

Figure 3 - Key model components and data sources. 3D seismic intersection, 3D porosity inversion intersection, seismic derived surface of the base of the Mt. Simon Formation, layer from geocellular model porosity model, and well CCS1 gamma ray log. 


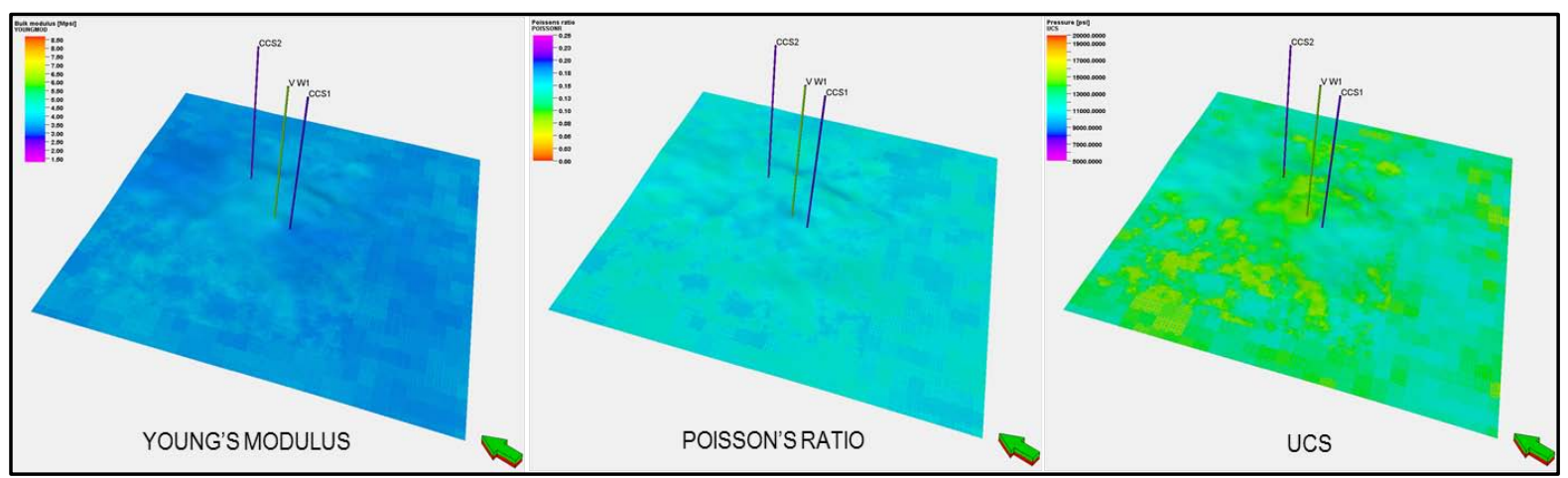

Figure 4 - Rock mechanical properties within the Mt. Simon A Formation. In this figure the properties are propagated using elastic impedance products as a trend guide.

\section{Reservoir Response}

\section{Description}

The component of observed microseismicity attributable to $\mathrm{CO}_{2}$ sequestration activities may be thought of as the "reservoir response" to a transient perturbation of the preinjection reservoir stress-strain state. In cases such as at the IBDP where injection pressures are significantly below fracture pressure, microseismicity is believed to be caused by both incremental stress release along pre-existing zones of weakness as increasing pore pressure reduces effective stress, and by crushing type forces when pore pressure decreases. These zones of weakness may be related to structural or stratigraphic features. While microseismic activity is ultimately dictated by geomechanical conditions, both the geomechanical condition and the resulting microseismicity are highly dependent upon other controlling geological and hydrodynamic considerations such as stratigraphic features and preferential flow paths. Characterization of the event mechanisms and the development of plausible working predictive models must be performed within the geologic framework which facilitated the incorporation of multiple lines of indirect evidence into the analysis.

At the IBDP site this challenge has been approached using a workflow comprising the following main steps:

1. Microseismic data inversion - Source parameters are extracted from the observed microseismicity using FPS (Cipolla et al, 2011,2012), (Shi and Zion, 2003) and standard methods for source location (Geiger, 1912) and moment estimation (Brune, 1970).

2. Hydrodynamic response and reservoir simulation - The calibrated reservoir simulation model was developed from the static geologic model in order to provide pore pressure estimates during the period of observed microseismicity.

3. Coupled hydro-mechanical modeling - The hypothetical microseismic source features developed in Step 1 are included in the 3D MEM and coupled hydromechanical modeling is performed using the pressure output from Step 2.

4. Microseismic response modeling - Transient stress predictions from Step 3 are used along with assumed failure characteristics for microseismic source features 
to predict the characteristics of the microseismic energy radiated as the result of incremental stress release.

These process steps are described and results presented in the following sections.

\section{Microseismic Data Inversion}

Within a few months after the commencement of injection spatial trends began to emerge in the microseismic observations. Events began to cluster, with some clusters exhibiting distinct linearity. Figure 5 shows an aerial view of located microseismic events up to December 2012. By that time several linear trends had emerged with varying degrees of coherency. The most predominant trend is that of Cluster 4, which also displayed the most microseismic activity.

These linear trends are suggestive of faults or lineaments which may be releasing seismic energy through incremental reactivation due to effective stress change. Given this provision, the seismic data were revisited to look for evidence of the responsible structural features. No such features could be interpreted from seismic data even though extensive attribute analyses were employed. It was thereby concluded that the responsible features were either sub-seismic or the result of more complex interactions between basement rock and the overlying Mt. Simon Formation. The microseismic clusters could be loosely correlated with Pre-Cambrian surface topography, which is believed to be an expression of weathered Pre-Cambrian structural features. Richter-Gutenberg analysis of the data (Figure 6) shows a slope of -1 which indicates a tectonic mechanism (Guttenberg and Richter, 1956). The departure from slope of -1 above 0.4 magnitude may be attributed to a number of causes including poor statistical support or the existence of strata-bound source mechanisms (Eaton et al, 2014).

In addition to the location and calculation of moment magnitude for each event, an FPS analysis of the data was conducted. Figure 7 shows the FPS analysis for the entire population. The FPS analysis indicated a reasonable overall fit to N45E strike azimuth and 20 degrees inclination with some scatter indicating multiple orientations. The data were then separated into spatial clusters and the FPS analysis performed on a cluster-bycluster basis. Figure 8 shows the result of the FPS analysis for the predominant cluster (4), again yielding an azimuth of N45E. Figure 9 shows the azimuth of FPS results for each cluster highlighting the wide variation in event count and coherency between clusters which impact relative confidence in FPS results for different clusters.

The FPS analysis thus provided an indirect indication of the microseismic source mechanisms shown in Figure 9 which, although not substantiated through direct seismic imaging, could be used as a basis for further model-based integration. 


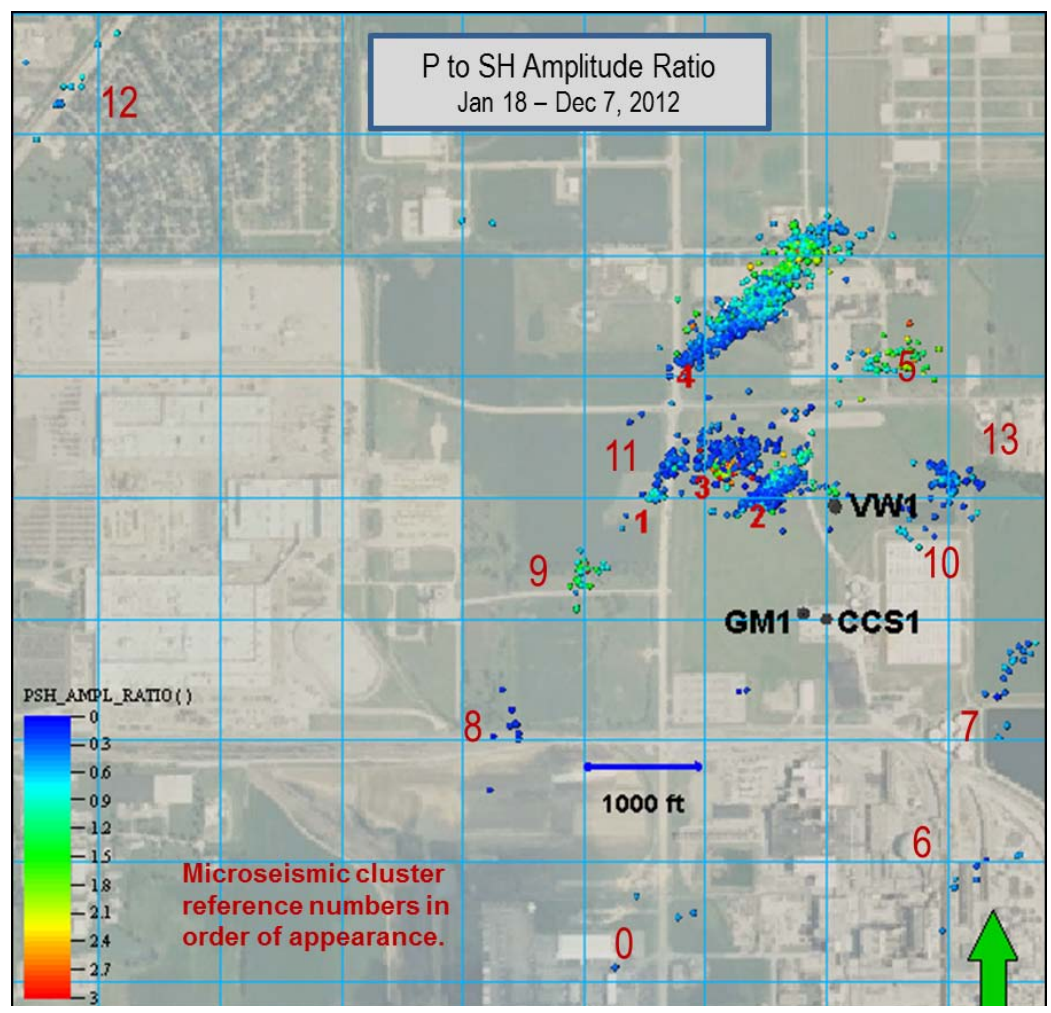

Figure 5 - Microseismic events and compressional (P) to shear (Sh) amplitude ratio used for FPS analysis.

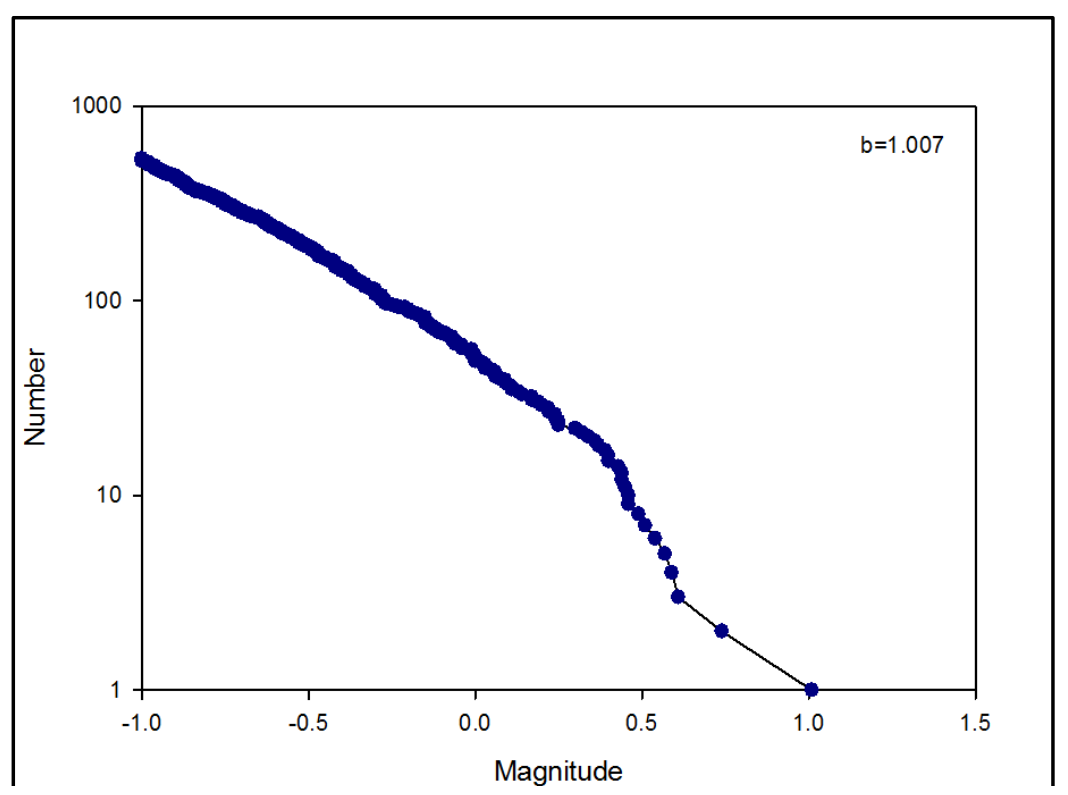

Figure 6 - Slope of the frequency-magnitude/Richter-Gutenberg is consistent with tectonic events. 


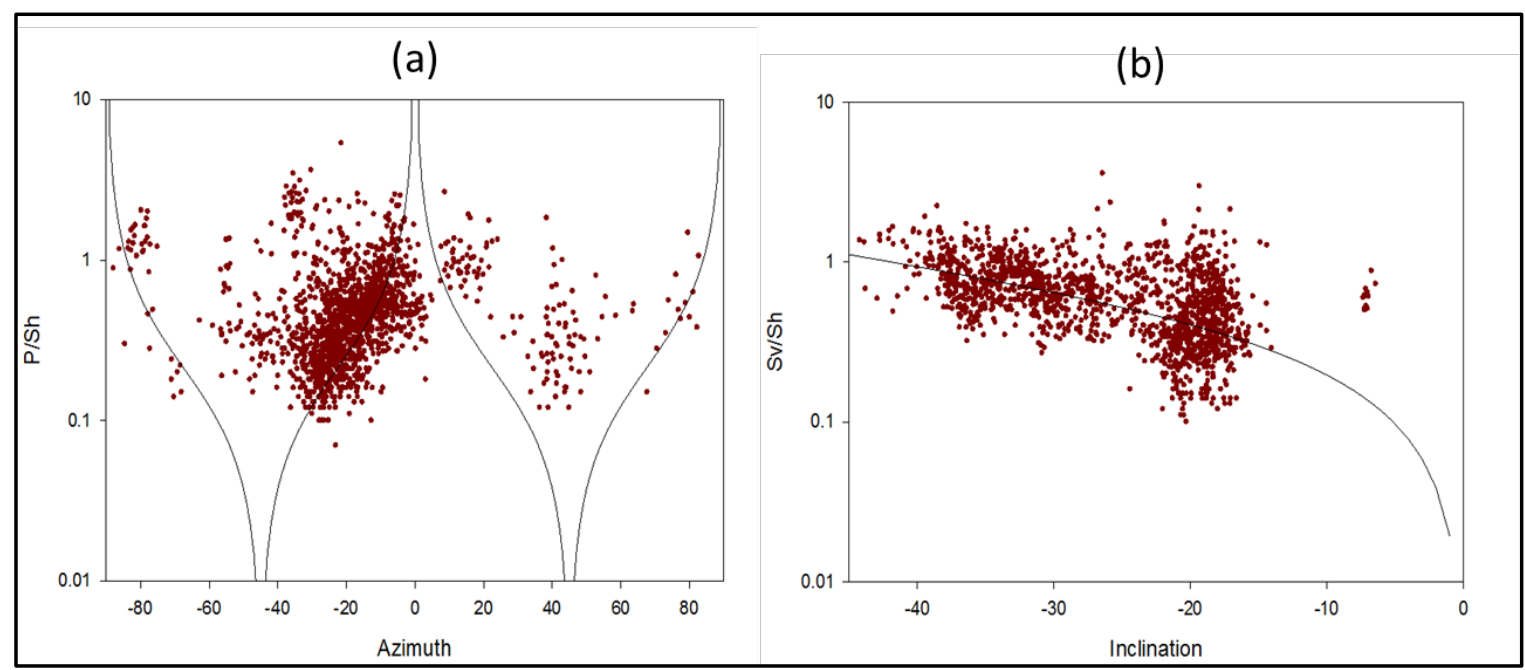

Figure 7 - (a) Observed amplitude ratios (red) plotted versus azimuth to sensor in CCS1 for all events indicating N45E strike for strike slip mechanism (b) using average azimuth of $20^{\circ}$ fits Sv/Sh vs angles of inclination for all events.

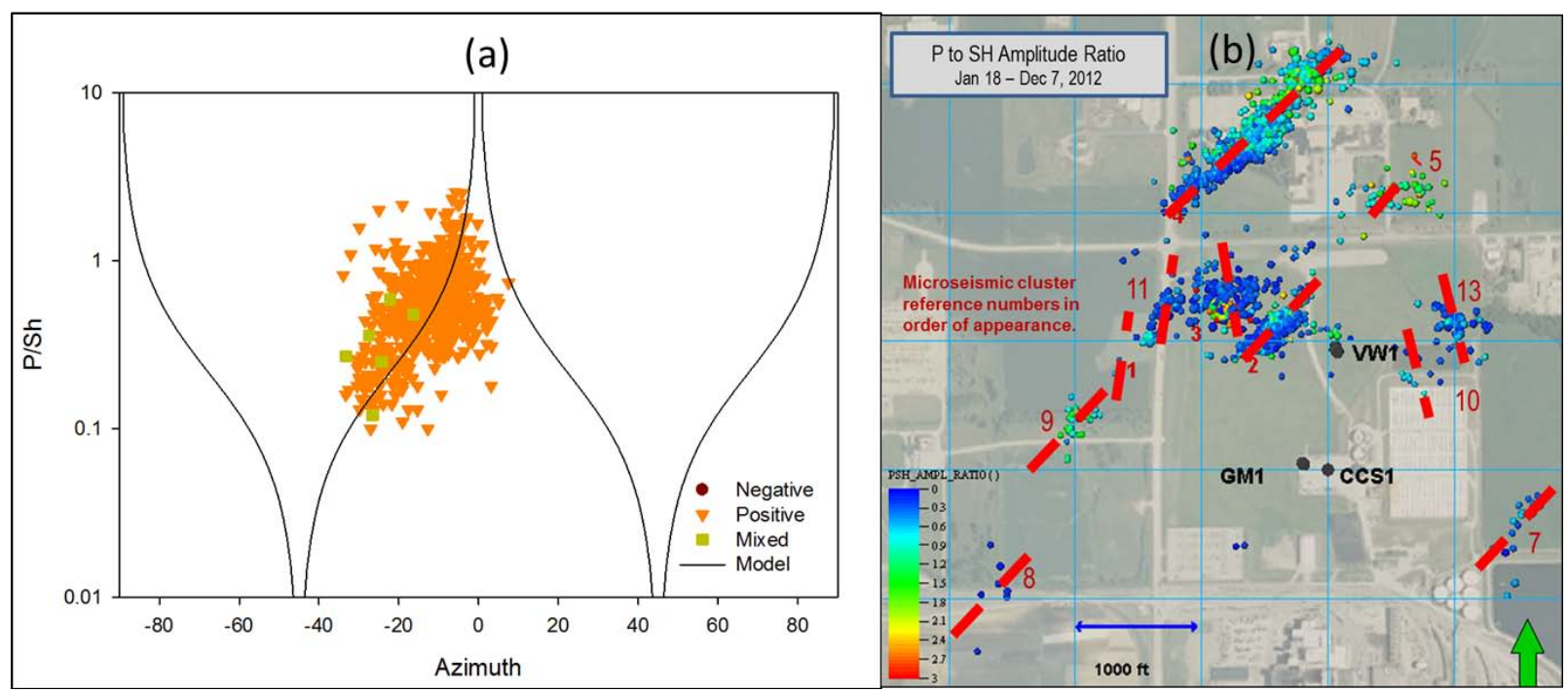

Figure 8 - (a) FPS analysis plot for events isolated as cluster 4 yielding strike orientation of N45E, (b) Polygons (red) showing strike orientation inverted using individual FPS analysis for all clusters. 


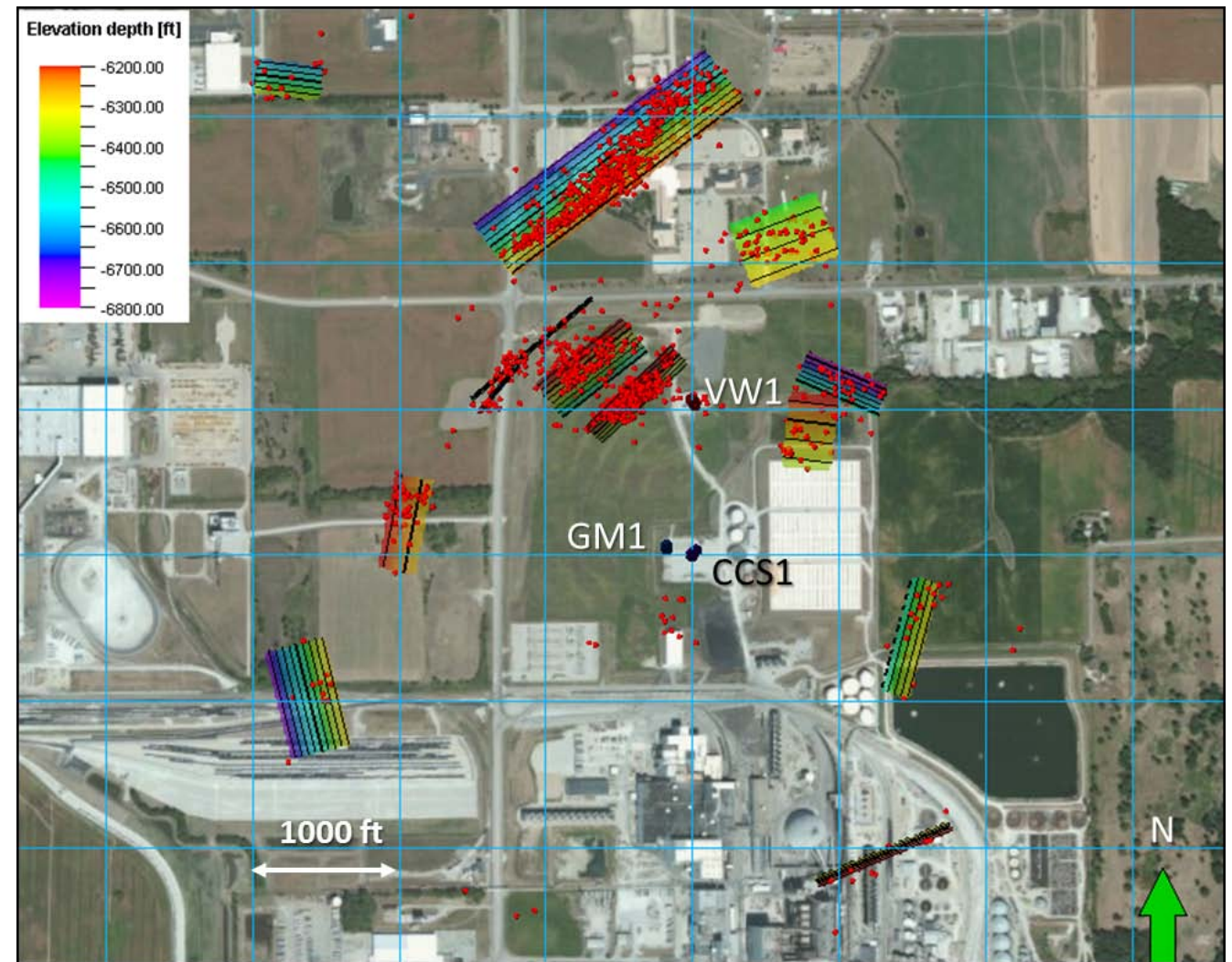

Figure 9 - Discrete features inverted from microseismic observations using FPS analysis.

\section{Hydraulic Response and Reservoir Simulation}

Next, the hydraulic response of the reservoir was investigated to understand the pore pressure behavior which directly impacts the characteristics of the observed microseismicity. High frequency real-time pressure observations are available in the IBDP injection well (CCS1) and at multiple levels within and above the injection zone in a monitoring well (VW1) located approximately 1,000 feet (304.80m) away from CCS1. Figure 10 shows pressure history in VW1 sampling ports along with injection rate and cumulative injected volume. Pressure ports are numbered from deeper to shallower with ports 2-5 located in the Mt Simon A (injection zone). Gaps in data on the plot were due to regulatory and project operational activities or gauge failure.

These data clearly indicate significant pressure isolation between the lower portion of the Mt. Simon A (where the injection well was perforated and labeled in Figure 10 as "Below Mudstone") and the upper portion (Figure 1 and labeled in Figure 10 as "Above Mudstone”). Pressure increase and response to injection rate variations are highly muted in Ports 4 and 5 as compared to Ports 2 and 3, which exhibit almost immediate response 
to changes in injection rate and pressure in CCS1. Prior to this observation the Mt. Simon A was felt to be a single hydraulically continuous unit with some baffling inhibiting vertical permeability. However, this observation led to re-evaluation of log data and inclusion of a strong discrete baffle (mudstone) separating the lower and upper portions of the Mt. Simon A Formation in the updated reservoir model. In fact, adding this feature was required to achieve a reasonable history match of the pressure data. This feedback between field data and model has proven to be critical in the selection of the completion interval for the second injection well for the ICCS project.

The fact that these events, as seen in Figure 9, are occurring and appearing in clusters indicates that the features are mechanically active. However, their hydraulic properties have yet to be determined. While it is as yet uncertain whether these are faults or stratigraphic features such as onlapping over basement structural highs, the potential for hydraulically sealing and/or non-sealing faults must be considered for purposes of the simulation model. If these features are hydraulically sealing then they must be included in the reservoir model in order to produce an accurate hydraulic response. The hydraulic characteristics of the features were tested through forward simulation modeling and inspection of pressure history matching for different scenarios (Figure 11). It was determined that the features were either non-hydraulically sealing or sealing but having hydraulic impact too small to be resolved from the available monitoring data. Based on these findings the implicit microseismic features were not included as hydraulic barriers in the reservoir simulation model. Figure 12 shows a cross section of the modeled plume from the updated reservoir model with the mudstone baffle included and no hydraulic boundaries at microseismic features.

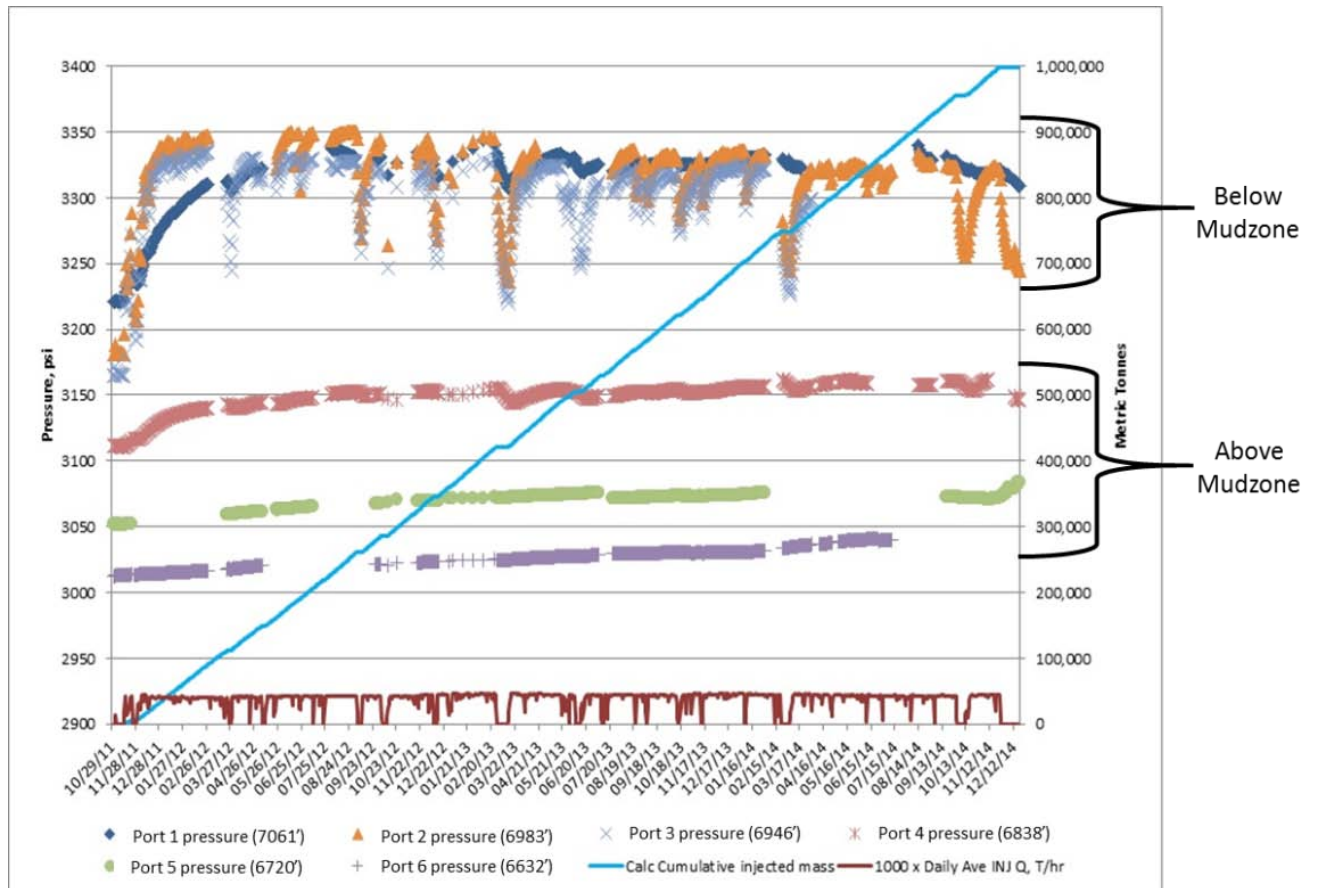

Figure 10 - Graph displaying Westbay multilevel groundwater characterization and monitoring system zones 1-6, cumulative injected mass, and daily average injection rate (X1,000) since just before the beginning of injection in late 2011. 


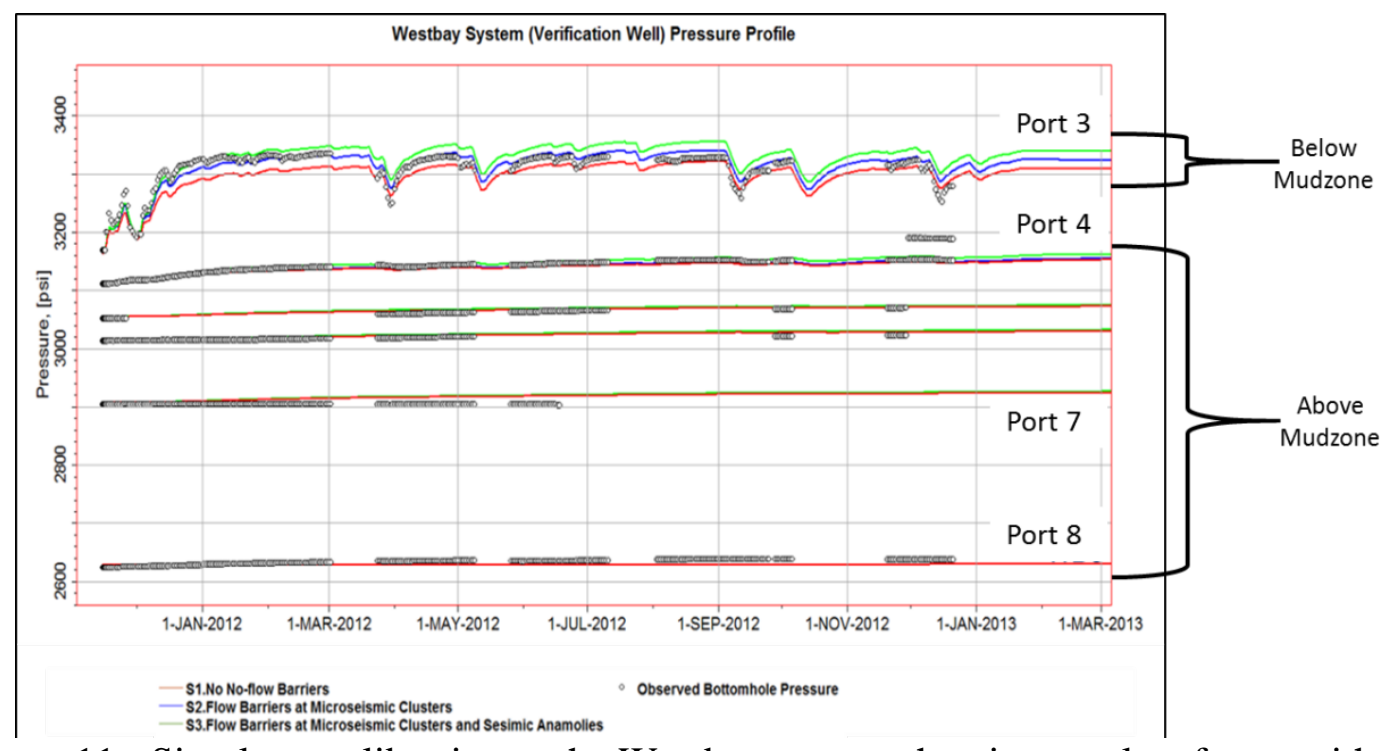

Figure 11 - Simulator calibration to the Westbay system showing results of tests with and without flow barriers at microseismic features. Mudzone refers to the low-permeability mudstone baffle.

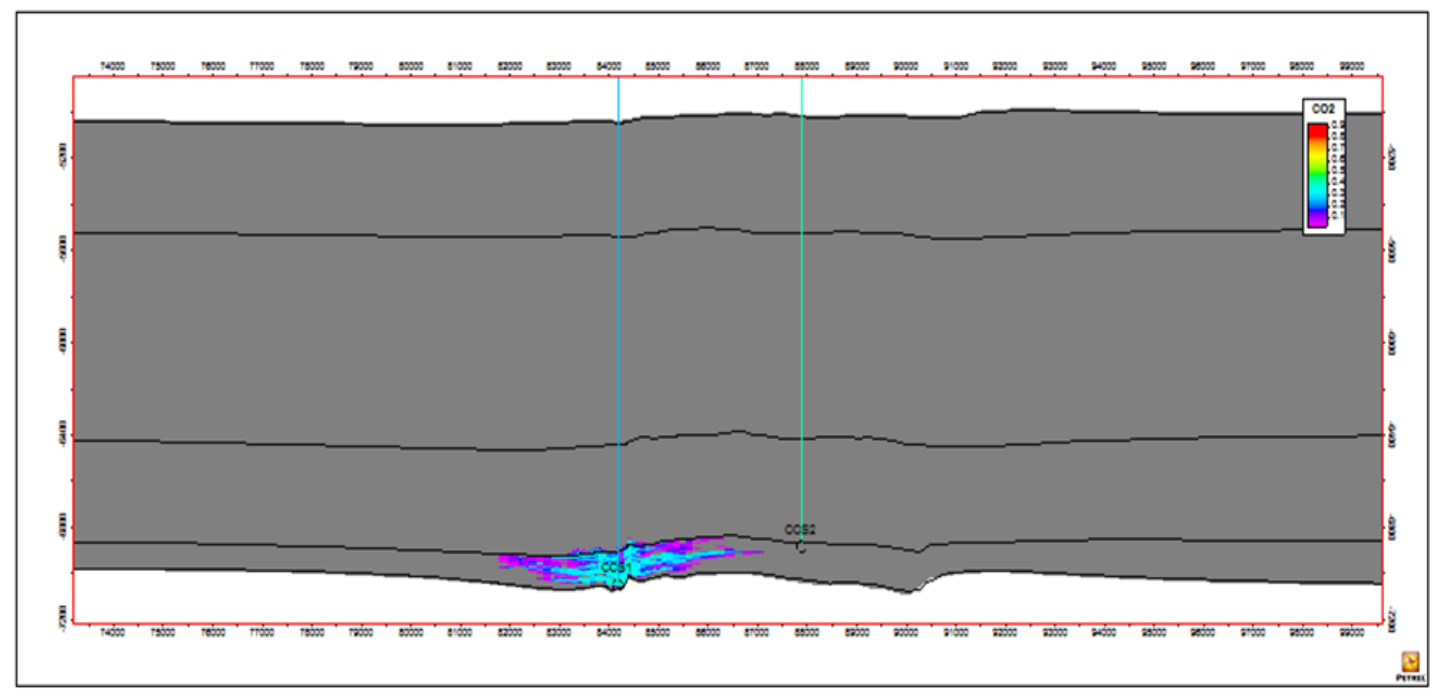

Figure 12 - Modeled $\mathrm{CO}_{2}$ plume cross section at end of injection in CCS1.

\section{Coupled Hydro-Mechanical Modeling}

Coupled hydro-mechanical modeling of the transient stress-strain response to injection of the reservoir was performed using the detailed geologic model, the calibrated reservoir model. A set of hypothetical double-coupled source features were included with locations 
and geometry derived from FPS analysis of observed clusters. These features were characterized as shear displacement source mechanisms which are anticipated due to the in-situ stress conditions. The coupled hydro-mechanical (Finite Element Model - FEM) and seismological modeling workflow is illustrated in Figure 13. The left side if the workflow diagram shows the static portion of the modeling workflow including the geologic framework and 3D MEM. The middle section of the diagram illustrates transformation of the static model to the dynamic model (FEM). The right side of the diagram shows the conversion of strain predictions from the FEM to radiated microseismic energy.

The features inverted from microseismic data through FPS (shown in Figure 9) were included in the 3D MEM as planes of mechanical weakness with respect to the surrounding matrix. Although the exact geologic form of the planes of weakness had not been resolved typical values for hypothetical fault normal and shear stiffness were used as a starting point for the discontinuity zones and then adjusted until plastic failure was observed in the model. Properties examined included fault friction coefficient, fault normal stiffness, and fault shear stiffness. Figure 14 shows the initial condition of the hydro-mechanical model with the critical stress state of each feature and direction of insitu minimum stress indicated (red lines). The critical stress state of each feature (color shaded planes) depends on its failure properties and its orientation with respect to the insitu stress field. Note that features aligned parallel with the minimum stress direction are less critically stressed. Reservoir simulation pressure updates to be used for the FEM were selected to coincide with significant formation pressure variations and are shown in Figure 15.

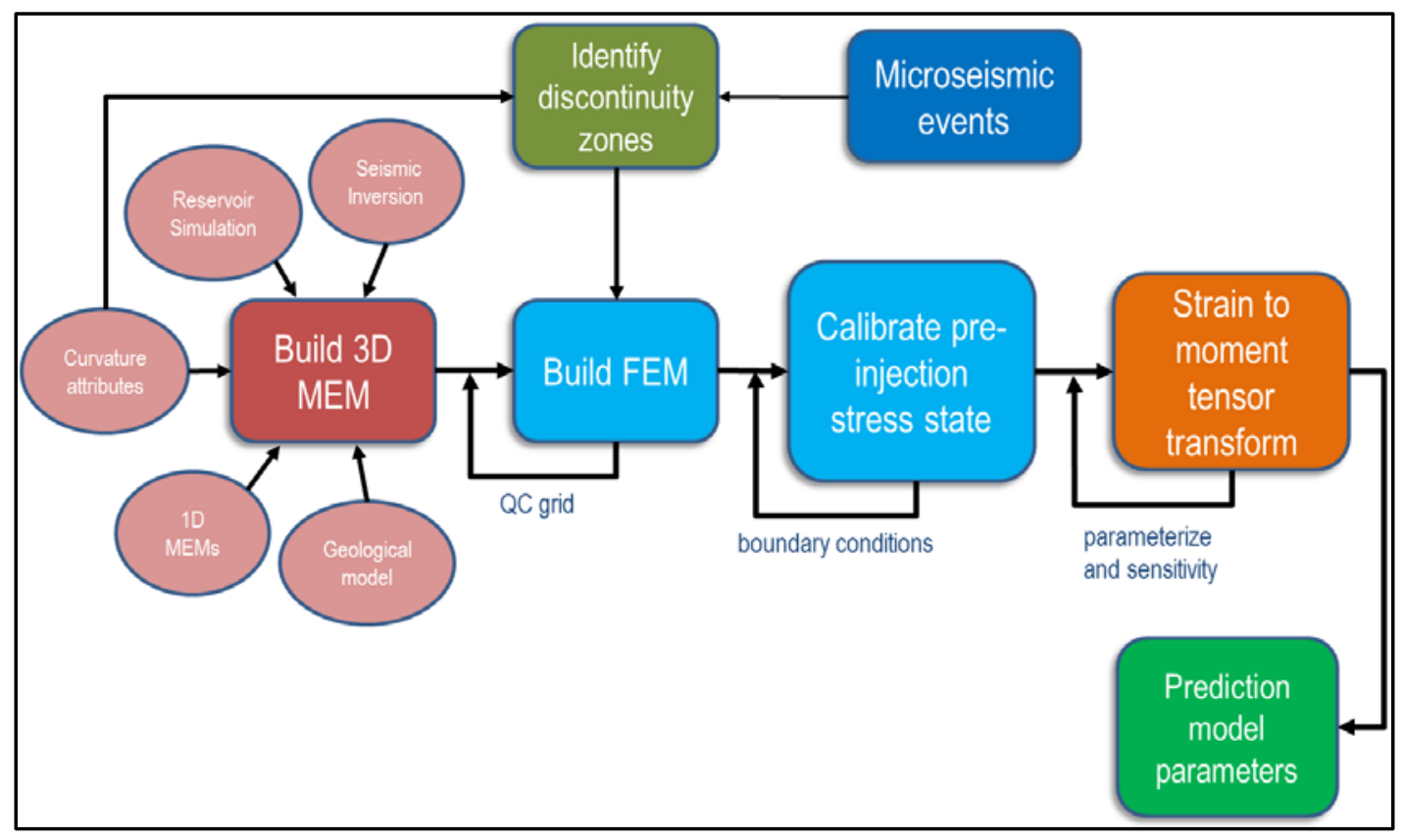

Figure 13 - Workflow for models used in the study with key inputs. 


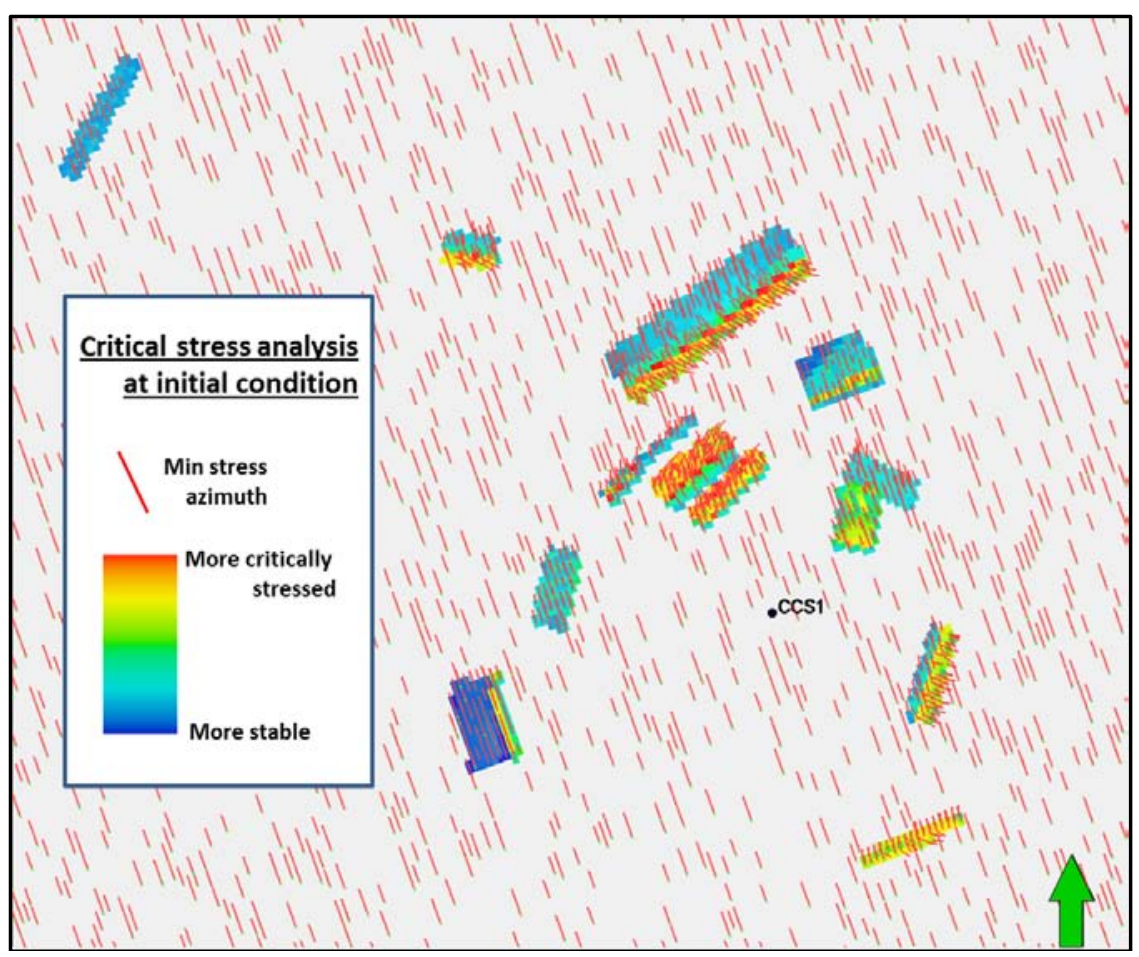

Figure 14 - Failure feature critical stress state (shaded planes) and in-situ stress orientation (red lines) at FEM initialization.

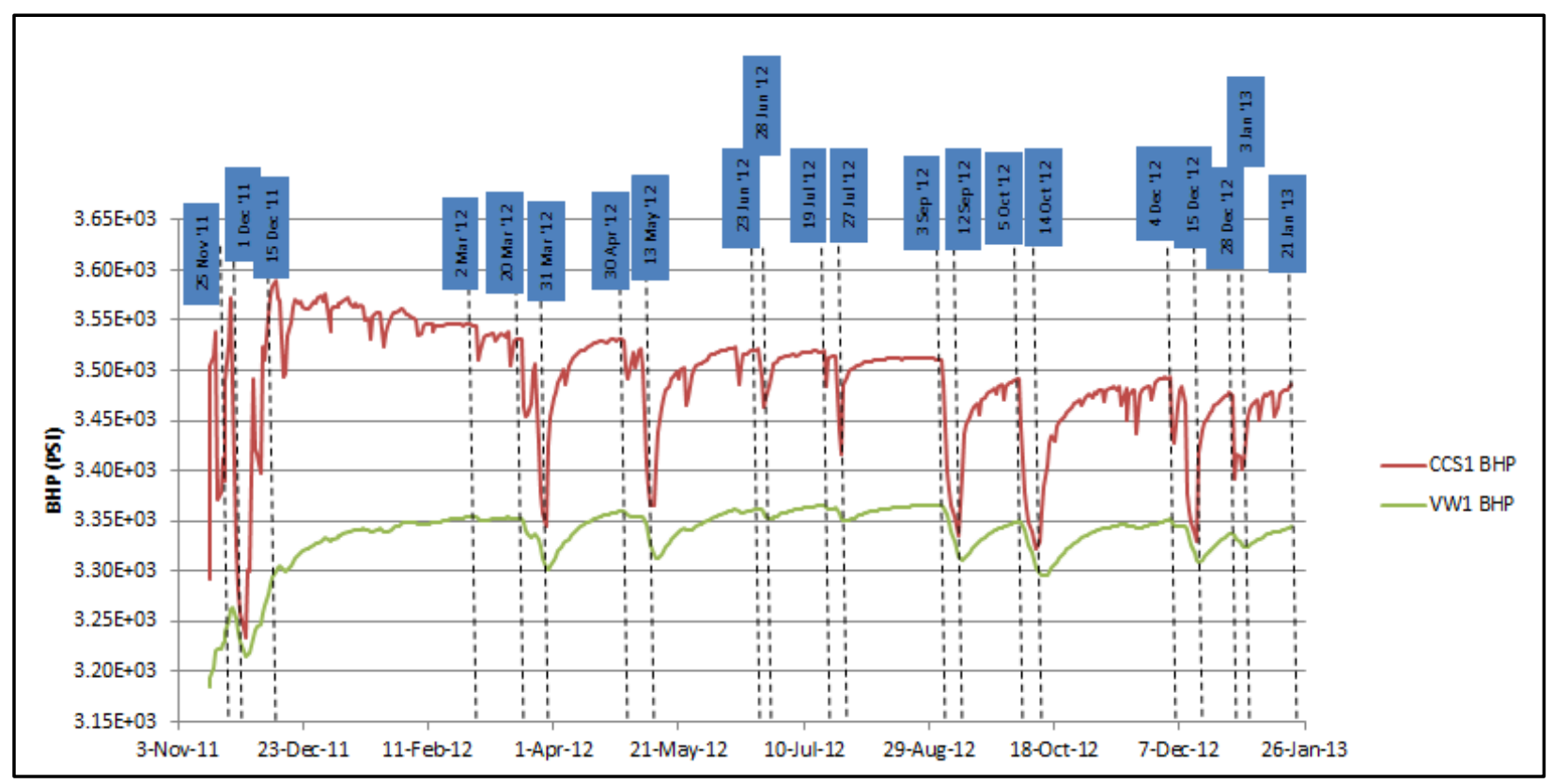

Figure 15 - Bottomhole pressure measured at the injector (CCS1) and monitor (VW1) well. Dashed vertical lines indicate pressure steps that were chosen for input to the FEM simulations. 


\section{Microseismic Response Modeling}

3D stress-strain volumes from the FEM along with the failure properties were used to compute the energy release from incremental failures along the hypothetical faults. These data were then used to compute moment tensors for the failure events using a strike-slip assumption consistent with both the FPS analysis and with the expectation given the insitu stress regime.

The last step of the modeling process was to attempt to history match the general event location, timing, and magnitude characteristics through adjustment of under-constrained feature properties. It was found that there is minimal impact on microseismic events over a wide range of fault stiffness properties. Figure 16 shows the results of fault stiffness sensitivity tests using three sets of hypothetical fault characteristics (stiff, medium, and soft). Other parameters studied included coefficients (volume of rock impacted and energy conversion efficiency) used in the transform from plastic strain to microseismic event.

Figures 16 through 18 show the results of initial modeling efforts. As seen in Figure 16, modeled microseismic events appear by definition at the prescribed failure planes. Moderate success was achieved toward the objective of approximating the relative number of events observed at each feature. Figure 17 illustrates that modeled microseismicity starts early compared to observations. Figure 18 shows that the model under-predicts moment magnitude. Figures 17 and 18 highlight the impact of pressure step selection on modeling results. All modeled microseismicity occurs in association with pressure updates, resulting in modeled events occurring in bursts rather than gradually over time as in observed in nature. Planned updates to the model include a significant increase in the frequency of pressure updates.

These results highlight weaknesses in the current model and have provided useful information about parameter studies and data gaps with respect to feature characterization and seismic energy conversion. Some of these data gaps are currently being investigated through laboratory testing and modeling under the auspices of the United States Department of Energy (DOE) funded Illinois State Geological Survey (ISGS) Center for Geologic Storage of $\mathrm{CO}_{2}$ Energy Frontiers Research Center. 


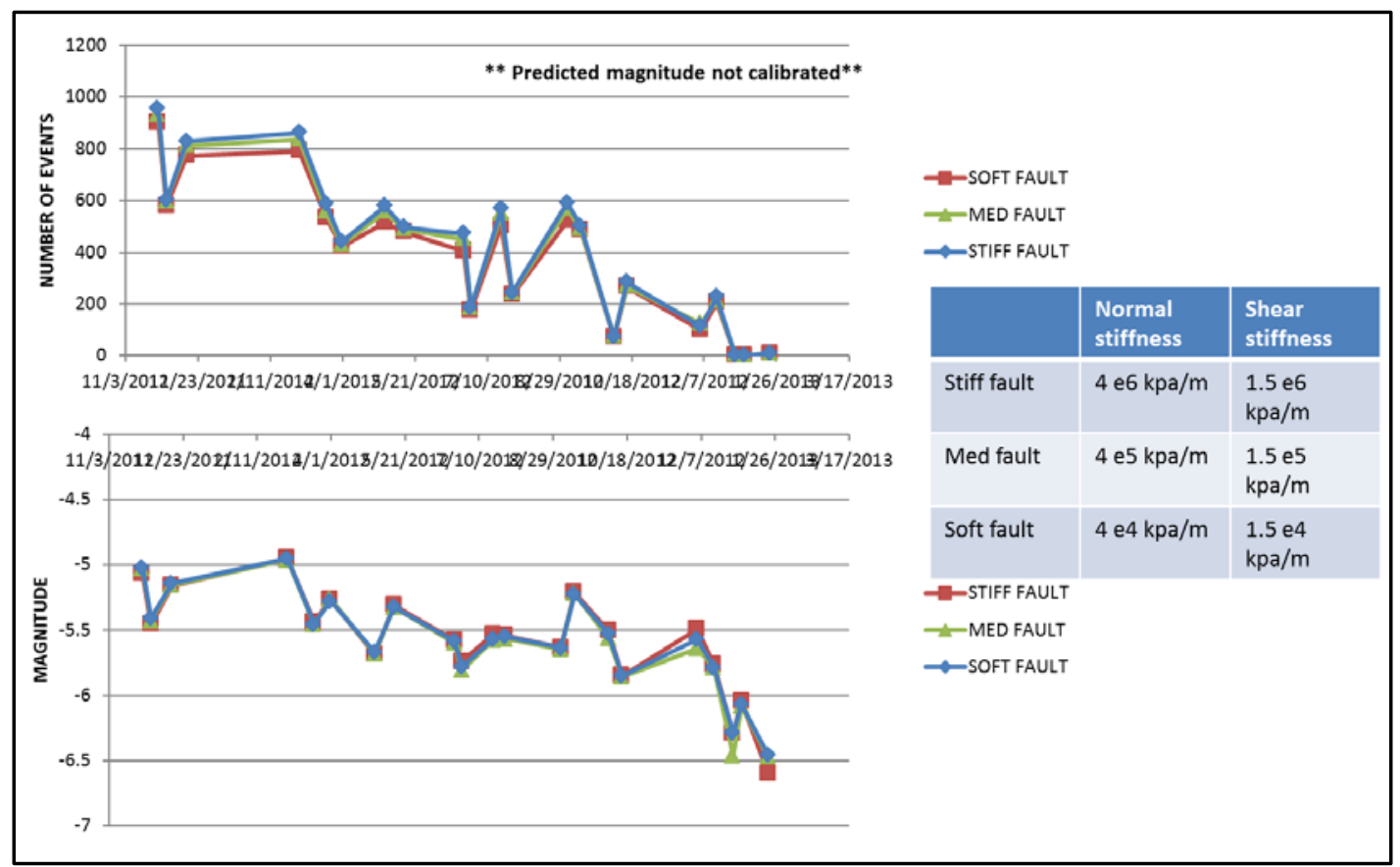

Figure 16 - Sensitivity of modelled microseismic events and magnitude to fault stiffness properties. Even with 2 orders of magnitude change in normal and shear stiffness, there is very little change with the microseismic events.

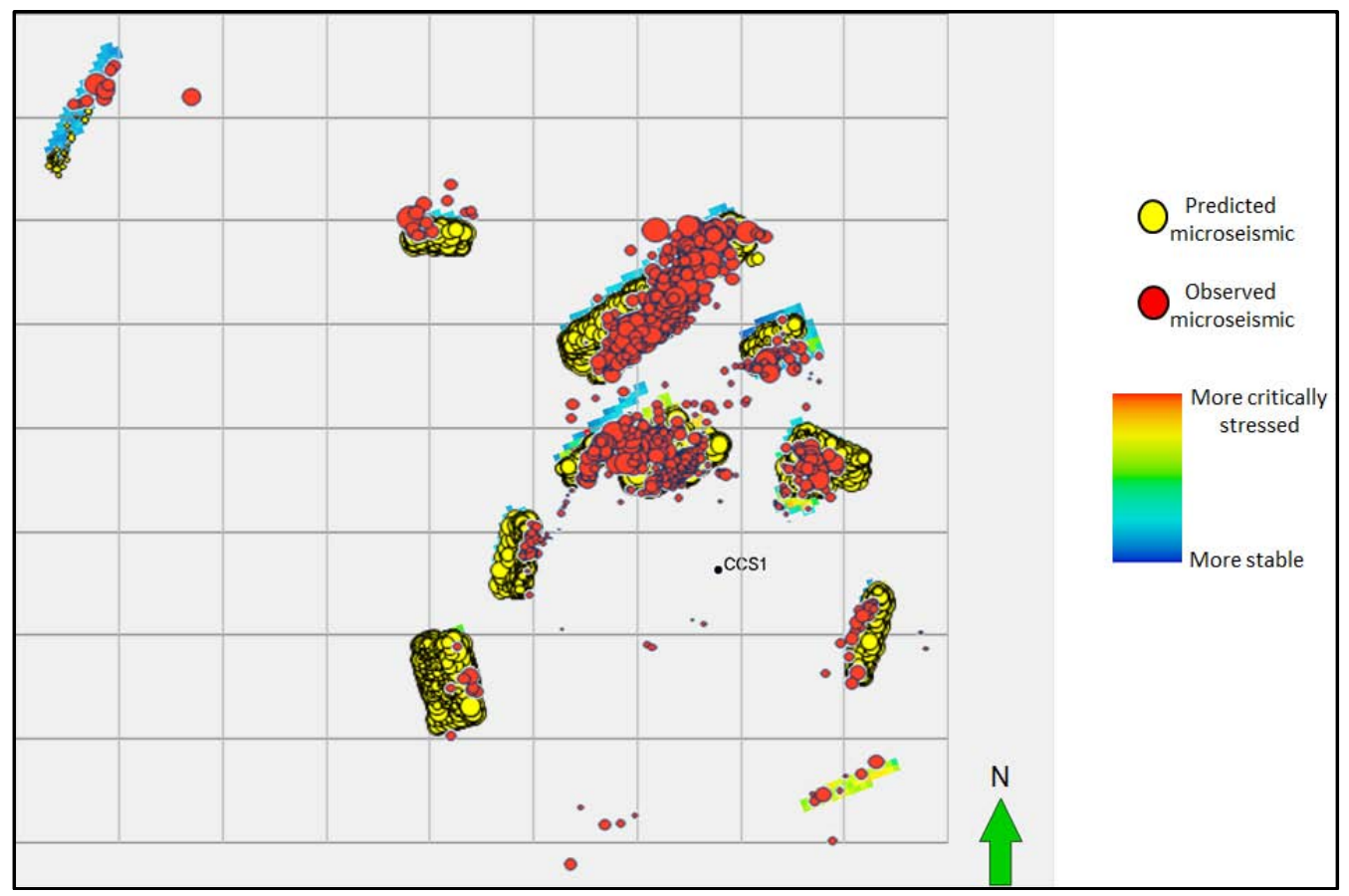

Figure 17 - Location of modeled microseismic events (yellow) and measured microseismic events (red). Modeled microseismic events are over predicted on several of the planes, which may indicate the need to vary fault properties. 


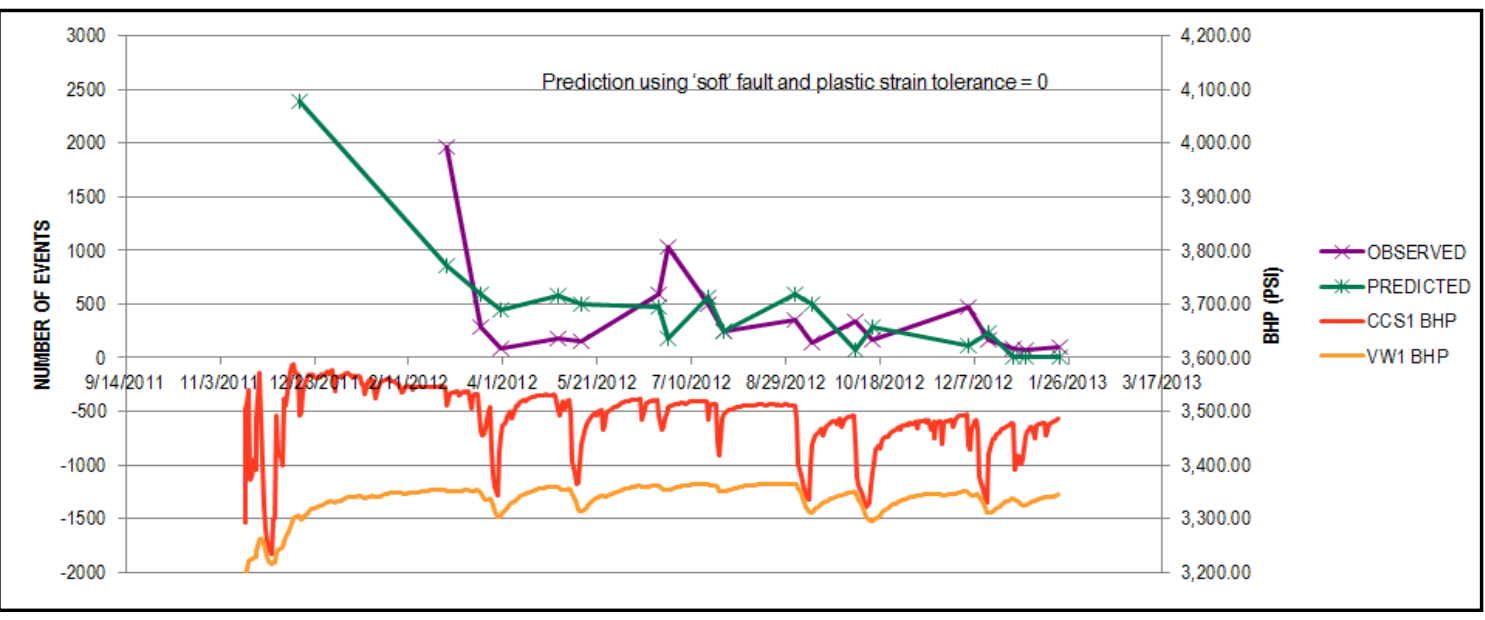

Figure 18 - Number of modeled microseismic events (green) and observed microseismic events (purple) with time. Observed events were summed over the same time step interval used in the FEM pressure step.

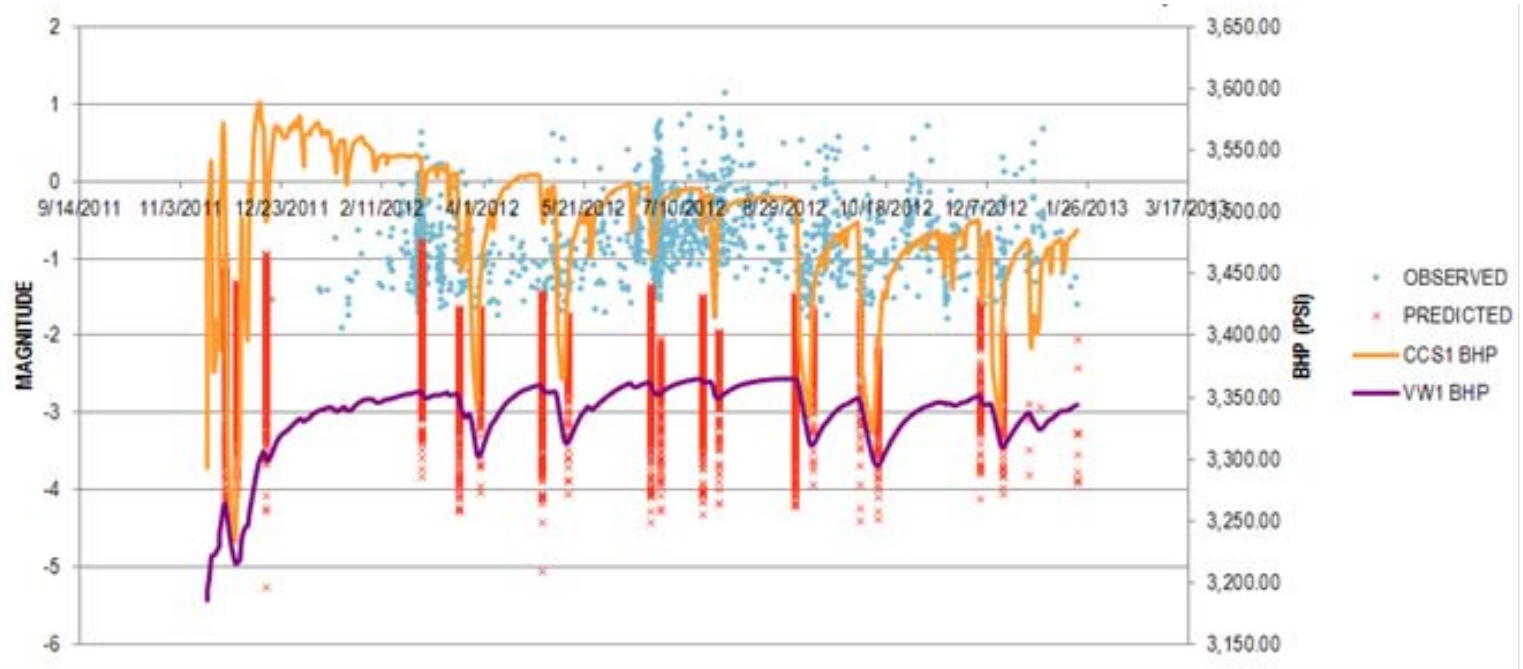

Figure 19 - Comparison of modeled microseismic events (red) at time steps to measured microseismic events (blue). The magnitude of modeled events is lower than measured due in part to model cell size.

\section{Utilization and Feedback}

\section{Overall Benefits of the Microseismic Analysis}

The IBDP has benefitted from interaction between microseismic monitoring, site characterization data collection, field development planning, and continuing research. Each well drilled has provided additional geological, geophysical, and/or geomechanical information. While the effort to develop a calibrated predictive hydro-mechanical 
microseismic response model (as described in the previous sections) continues, the work to-date has provided several valuable benefits, including:

- Inversion of the microseismic data, although not verified by direct seismic interpretation, supported a conceptual double coupled source mechanism which was geologically and geomechanically consistent with other available data and current geologic and mechanical models. This inversion supported the introduction of features into the model that were otherwise unobservable based on existing datasets, bringing the model closer to a realistic state. Ongoing analyses including seismic interpretation and geomechanical testing are aimed at resolving the geologic characteristics (structural or stratigraphic) of source mechanisms.

- Hydraulic data analysis has suggested the low-permeability baffle significantly impacts the hydraulic behavior of the reservoir and the microseismic response to injection-induced pore pressure variations. This observation contributed significantly to ongoing field development as the second project (ICCS) was planned and developed by suggesting that the second injection well be perforated above the baffle.

- The effort to integrate the information (through numerical modeling) has revealed critical data gaps with respect to mechanical characterization of pre-existing planes of weakness. These data gaps are being investigated under the auspices of the Energy Frontiers Research Center, Center for Geological Storage of $\mathrm{CO}_{2}$, an Energy Frontier Research Center funded by the U.S. Department of Energy, Office of Science.

- Microseismic observations from the existing monitoring array have provided feedback to guide design of additional monitoring resources which have been added in order to improve location and characterization of the observed activity as it occurs further from the injection well.

The following sections describe how the microseismic analysis has been used to actively manage potential injection-induced microseismicity through operational intervention and well design.

\section{Utilization for Injection Operations}

During the process of analyzing microseismic activity and operational data from the IBDP RTAC* real-time acquisition and control software it was noted that subtle changes in microseismic activity occur during injection start-up and shut-down. Figure 19 shows a time series of microseismic activity and injection rates using an injection rate cut off of at least 36 tonnes per day to display microseismic events. Increased microseismicity during significant rate variations is evident. Figure 20 shows histograms of microseismic event moment magnitude separated by shut-in versus injection using the 36 tonnes/day cutoff to define injection. Two statistically distinct populations are observed with the shut-in 
events being of slightly lower magnitude. Figure 21 shows the locations of injection events color-coded as injection (orange) and shut-in (blue).

To achieve injection at supercritical conditions, the $\mathrm{CO}_{2}$ facility uses two compressors in series. Normal operating procedure at the start of the project was to put all compressors online at the same time. On the basis of the microseismic analysis new operational procedures were implemented for controlled start-up and shut-down whereby compressors were brought online one at a time. The new procedure minimized the unnecessary creation of microseismicity resulting from controllable operational activities.

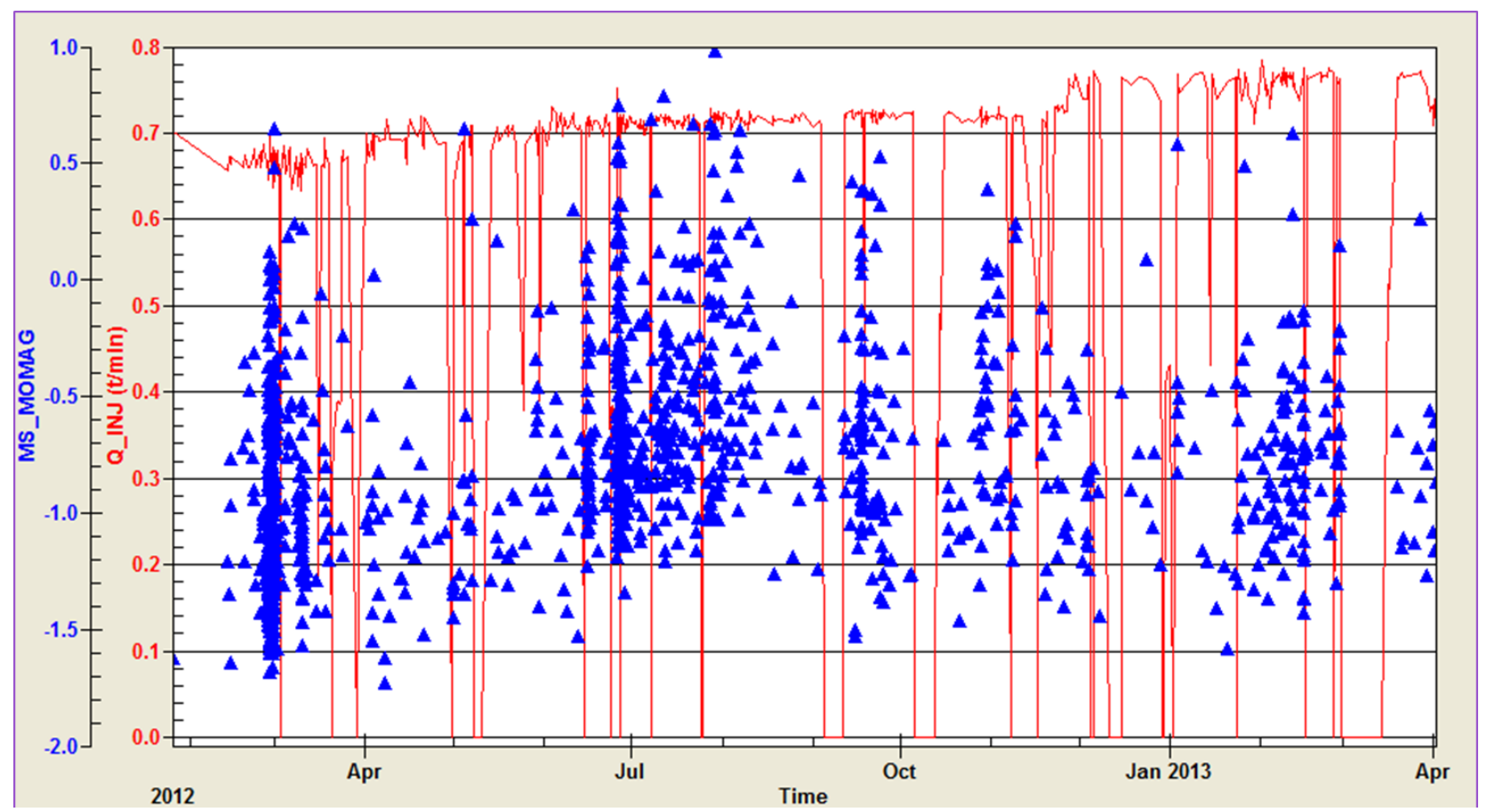

Figure 20 - Microseismicity during injection and start-up and shut-down procedures. 


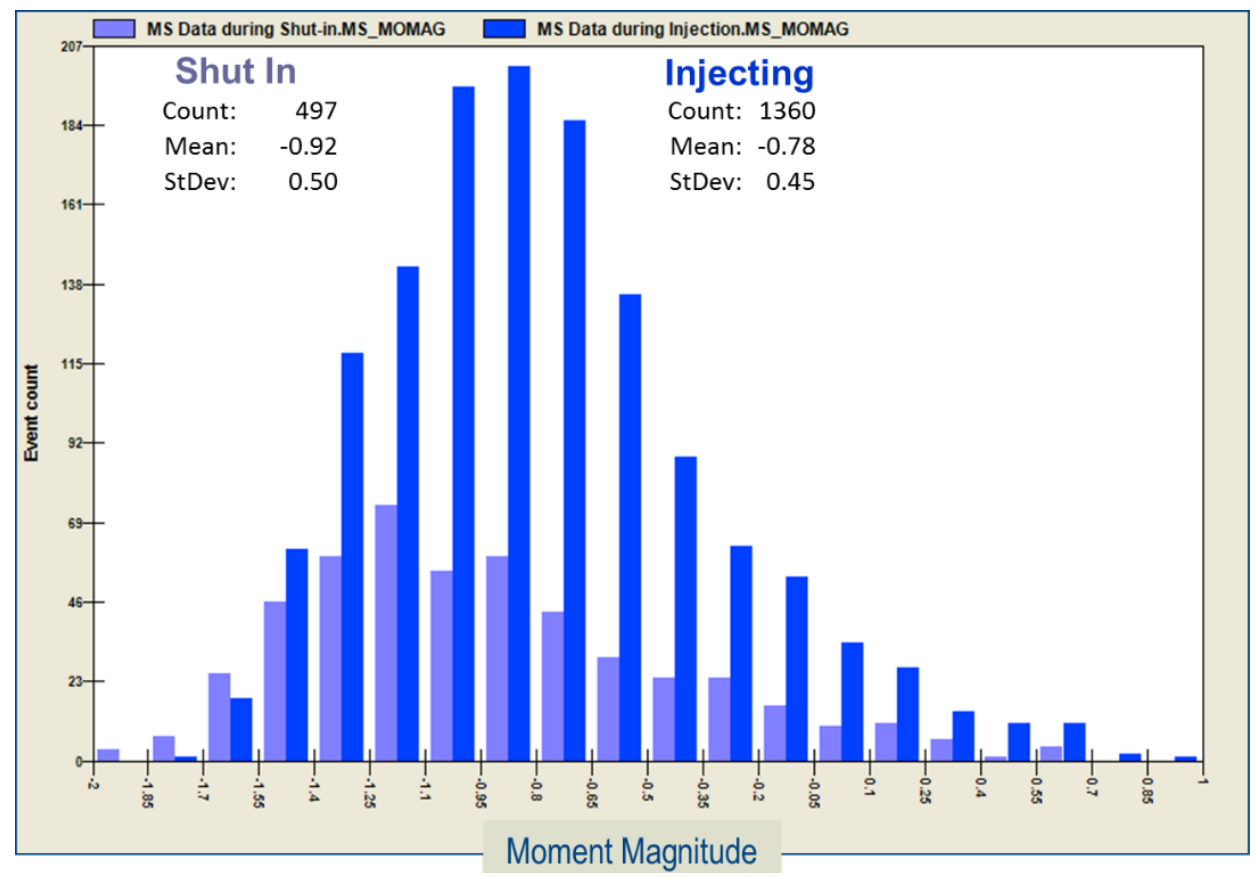

Figure 21 - Microseismic event count and moment magnitude during shut-in vs. injecting periods

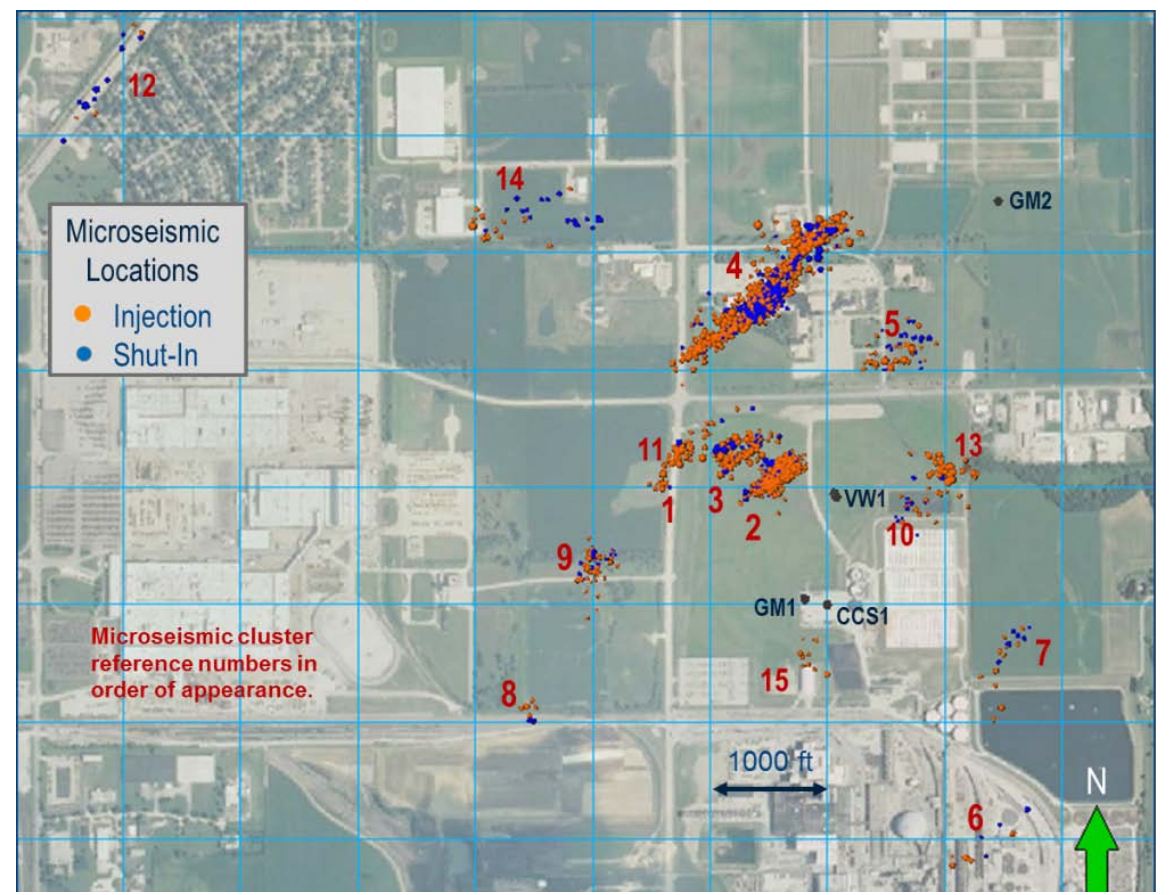

Figure 22 - Microseismic locations of injection versus shut-in events 
The microseismic analysis has also had an impact on completion design for the ICCS Project injection well (CCS2). Microseismic activity is located primarily in in the lower part of the Mt. Simon and underlying formations as illustrated in Figure 22. Pressure monitoring data (Figure 11) indicates that these events are confined to the area below the mudstone pressure baffle.

The original completion design for the new well included both the lower and upper parts of the Mt Simon A Formation, both above and below the mudstone zone. Based on the location of observed microseismicity for IBDP, the anticipated impact of the mudstone baffle, and the assessment that the new well would be able to achieve the required injection rates even if completed over a shorter interval than previously estimated, the completion plan for the new well was altered to include only the upper part of the Mt. Simon A Formation. In this way, it is believed that the current microseismic event locations will be isolated, at least in part, from pore pressure increase caused by injection in the new well.

Figures 22 and 23 show cross sections from the reservoir simulation for both the CCS1 plume after CCS1 shut-in, and the anticipated CCS2 plume with CCS2 completed in the entire Mt. Simon A interval (Figure 23) and only the upper portion of the Mt Simon A (Figure 24). Both models support the ability of the new well to achieve the required injection rates. However, the new completion design results in a much lower pressure increase in the volumes of rock showing observed microseismicity.

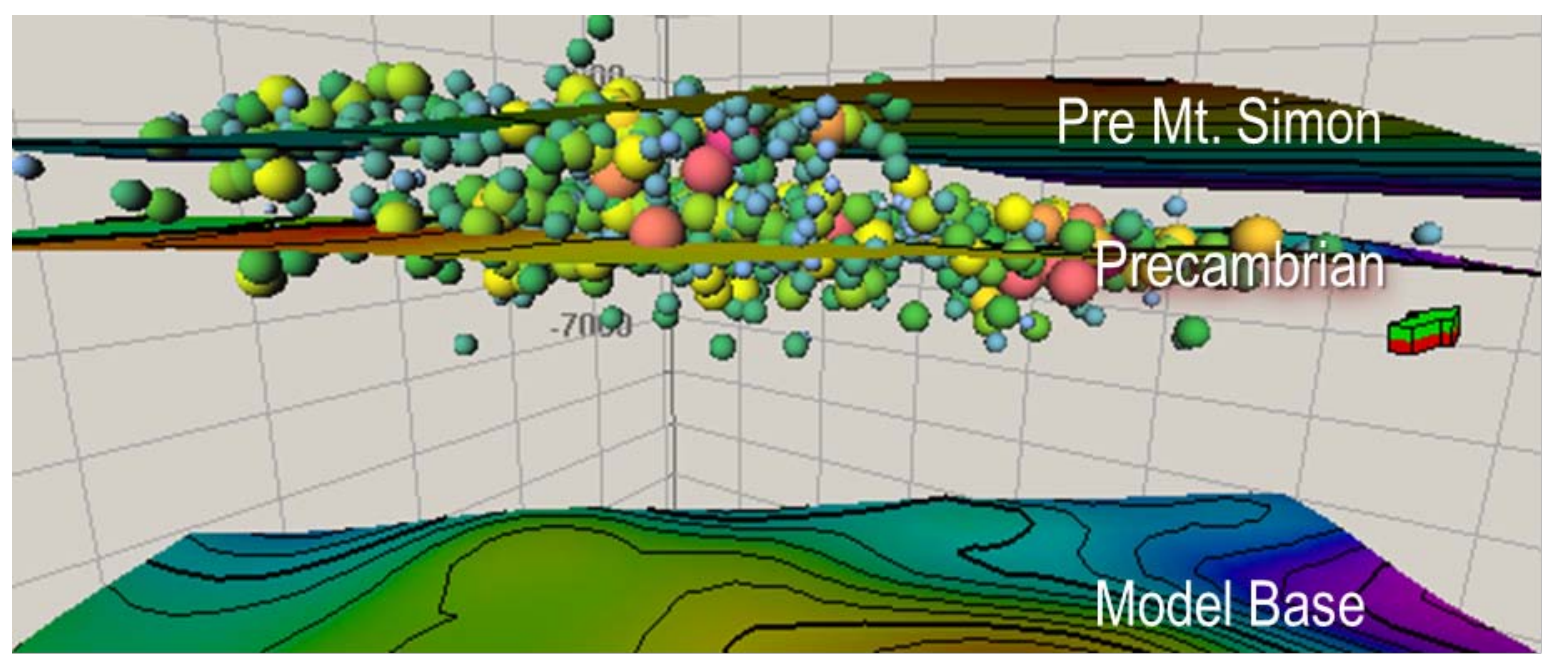

Figure 23 - Microseismic locations with respect to stratigraphy. 


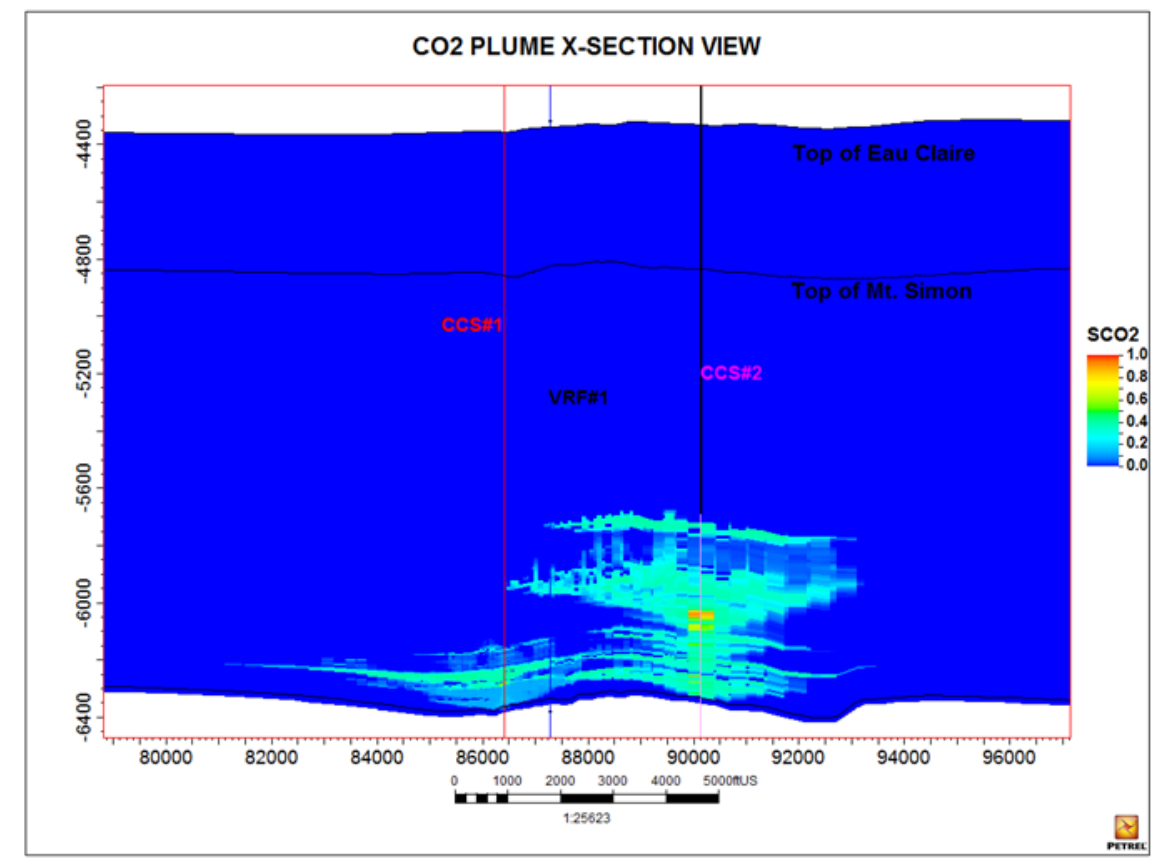

Figure 24 - Cross-section of modeled plumes from CCS1 and CCS2 with CCS2 completed in both lower and upper portions of the Mt. Simon A Formation.

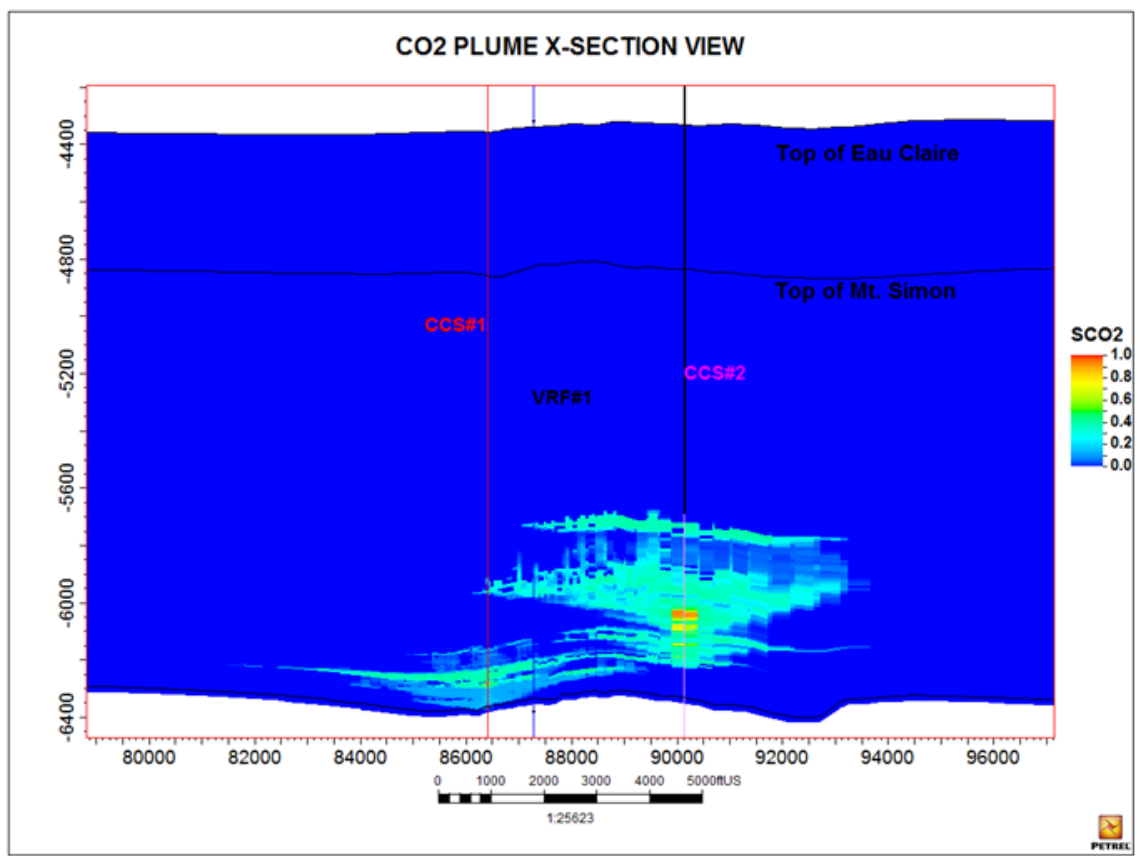

Figure 25 - Cross-section of modeled plumes from CCS1 and CCS2 with CCS2 completed in only the upper portion of the Mt. Simon A Formation.

\section{Summary}


The analysis of microseismicity at the IBDP site has evolved through the life of the project starting with pre-injection baseline observations and continuing into the postinjection phase. The desire to achieve a predictive capability led to the development of an integrated cross-disciplinary workflow in which accurate geologic context plays a central role. The process has been iterative, with monitoring data supporting model calibration and modeling results guiding further data acquisition efforts.

The microseismic reservoir response to $\mathrm{CO}_{2}$ injection under the conditions at IBDP is the result of a coupled interaction between fluid pressure, in-situ stresses, and pre-existing zones of compromised mechanical properties at distance from the injection well. This process has been modeled at the IBDP site using a workflow comprising 3D geologic, geomechanical, flow simulation, and coupled hydro-mechanical modeling. The lack of directly identifiable features $a$-priori in the available seismic data meant that the geometry and general characteristics of presumed source mechanisms for the model had to be derived from microseismic observations. This was accomplished using conventional methods including FPS analysis. The lack of direct evidence in seismic data placed increased emphasis on accurate geologic context for interpretation of modeled results.

While the effort to develop predictive capability is still in progress, the work performed to-date has produced several benefits, both in advancement of the technical solution, and in practical application for field operations. Establishment of the integrated workflow has provided an analytical framework within which specific data gaps have been identified, some of which may be closed through existing field or laboratory methods and others which require further basic research. Work towards improving this modeling capability continues under the ongoing IBDP monitoring and modeling program.

*Mark of Schlumberger

\section{Acknowledgement}

This work was conducted under the Midwest Geological Sequestration Consortium which is funded by the U.S. Department of Energy through the National Energy Technology Laboratory (NETL) via the Regional Carbon Sequestration Partnership Program (contract number DE-FC26-05NT42588) and by a cost share agreement with the Illinois Department of Commerce and Economic Opportunity, Office of Coal Development through the Illinois Clean Coal Institute.

\section{References}

Brune, J. N. (1970). Tectonic stress and the spectra of seismic shear waves from earthquakes, J. Geophys. Res. 75, 4997-5009 
C. Cipolla, S. Maxwell, M. Mack, R. Downie, A Practical Guide to Interpreting Microseismic Measurements, SPE 144067, Presented at the SPE North American Unconventional Gas Conference and Exhibition, Woodlands, Texas, 14-16 June, 2011.

C. Cipolla, S. Maxwell, M. Mack, M. Mack, Engineering Guide to Application of Microseismic Interpretations, SPE 152165, Presented at the SPE Hydraulic Fracturing Technology Conference, Woodlands, Texas, 6-8 Feb., 2012.

Eaton, D.W., Davidsen, J., Pedersen, P.K., Boroumand, N., Breakdown of the GutengergRichter relation for microearthquakes induced by hydraulic fracturing: influence of stratabound fractures, Geophysical Prospecting, (62), 806-818.

Freiburg, J.T., D.G. Morse, H.E. Leetaru, R.P. Hoss, and Q. Yan, 2014, A depositional and diagenetic characterization of the Mt. Simon Sandstone at the Illinois Basin - Decatur Project carbon capture and storage site, Decatur, Illinois, USA: Illinois State Geological Survey, Circular 583, 59 p. and 3 digital appendices.

Geiger, L. (1912). Probability method for the determination of earthquake epicenters from the arrival time only, Bull. St. Louis Univ. 8, 60-71.

Gutenberg, B., Richter, C. F., 1956. Magnitude and Energy of Earthquakes. Annali di Geofisica, 9: -15

Shi, Z. and Y. Ben Zion (2009), Seismic radiation from tensile and shear point dislocations between similar and dissimilar solids, Geophysical Journal International 179 (1), 444-458.

Stein and Wysession; An Introduction to Seismology, Earthquakes, and Earth Structure, 2003, Blackwell Publishing.

Will, R.A., Smith, V. Leetaru, H.E., Freiburg, J.T., Lee, D.W., Microseismic monitoring, event occurrence, and the relationship to subsurface geology, Energy Procedia, Volume 63, 2014, Pages 4424-4436, 12th International Conference on Greenhouse Gas Control Technologies, GHGT-12). 